\title{
The influence of light and relative humidity on the formation of epsomite in cadmium yellow and French ultramarine modern oil paints
}

\author{
Jessie Harrison ${ }^{1}$, Judith Lee $2^{2^{*}}\left(\mathbb{D}\right.$, Bronwyn Ormsby $^{2}$ and David J. Payne ${ }^{1,3}$
}

\begin{abstract}
The effect of relative humidity $(\mathrm{RH})$ and light on the development of epsomite $\left(\mathrm{MgSO}_{4} \cdot 7 \mathrm{H}_{2} \mathrm{O}\right)$ in Winsor \& Newton cadmium yellow (CY) and French ultramarine (FU) artists' oil colour paints was investigated. Tube paint samples were aged for 12 weeks at either $50 \%$ or $75 \% \mathrm{RH}$, under ambient light (200 $\pm 1 \mathrm{~lx})$, elevated light $(11,807 \pm 328 \mathrm{~lx})$, and neardark conditions. Aged paint samples were characterised using light microscopy (LM), scanning electron microscopy (SEM), energy dispersive X-ray spectroscopy (EDX), attenuated total reflectance Fourier transform infrared spectroscopy (ATR-FTIR), X-ray diffraction (XRD), and X-ray photoelectron spectroscopy (XPS). Results indicated that ageing at $75 \% \mathrm{RH}$ in elevated light conditions, promoted the formation of hydrated magnesium sulphate $\left(\mathrm{MgSO}_{4} \cdot 6-7 \mathrm{H}_{2} \mathrm{O}\right)$ crystals on the surface of both paints. The formation of sodium sulphate $\left(\mathrm{Na}_{2} \mathrm{SO}_{4}\right)$ as a degradation product of French ultramarine oil paints after ageing at $75 \% \mathrm{RH}$ in elevated light conditions is described. The formation of magnesium sulphate crystals in the absence of elevated $\mathrm{SO}_{2}$ is a new finding. For both cadmium yellow and French ultramarine oil paints, the pigments present are a likely source of sulphur, enabling the formation of sulphate salts, i.e., cadmium sulphide (CdS) yellow, and the sulphur radical anions $\left(\mathrm{S}_{3}{ }^{-}\right)$present in ultramarine pigment. Sulphur-containing impurities arising from pigment manufacture are an additional possibility. It was previously theorised that epsomite formation in water-sensitive twentieth century oil paintings resulted from exposure to the elevated atmospheric sulphur dioxide $\left(\mathrm{SO}_{2}\right)$ levels of the 1950s-1970s. This study demonstrates that hydromagnesite-containing cadmium yellow and French ultramarine oil paints of any period may be vulnerable to water-soluble sulphate salts formation and that this process is promoted by exposure to light and high (75\%) RH environments. The formation of sulphate salts as a degradation product is known to contribute toward the development of water sensitivity of modern oil paintings which can pose significant challenges to conservation. Therefore this study highlights the importance of minimising exposure to light and raised relative humidity for paintings containing such CY and FU oil paint passages, to help slow down these types of degradation phenomena which have implications for preservation.
\end{abstract}

Keywords: Water-sensitivity, Epsomite, Magnesium sulphate, Relative humidity, Cadmium yellow, French ultramarine

*Correspondence: judith.lee@tate.org.uk

${ }^{2}$ Conservation Department, Tate, Millbank, London SW1P 4RG, UK

Full list of author information is available at the end of the article

\section{Introduction}

Epsomite $\left(\mathrm{MgSO}_{4} \cdot 7 \mathrm{H}_{2} \mathrm{O}\right)$ has been identified as an artists' oil paint degradation product with high water solubility, and is believed to contribute towards water sensitivity increasingly encountered in twentieth and twenty-first century oil paintings [1-5].
Springer Open

(c) The Author(s) 2021. Open Access This article is licensed under a Creative Commons Attribution 4.0 International License, which permits use, sharing, adaptation, distribution and reproduction in any medium or format, as long as you give appropriate credit to the original author(s) and the source, provide a link to the Creative Commons licence, and indicate if changes were made. The images or other third party material in this article are included in the article's Creative Commons licence, unless indicated otherwise in a credit line to the material. If material is not included in the article's Creative Commons licence and your intended use is not permitted by statutory regulation or exceeds the permitted use, you will need to obtain permission directly from the copyright holder. To view a copy of this licence, visit http://creativecommons.org/licenses/by/4.0/. The Creative Commons Public Domain Dedication waiver (http://creativeco mmons.org/publicdomain/zero/1.0/) applies to the data made available in this article, unless otherwise stated in a credit line to the data. 
Epsomite formation within this context relates to the use of magnesium carbonate $\left(\mathrm{MgCO}_{3}\right)$ or hydromagnesite $\left(\mathrm{Mg}_{5}\left(\mathrm{CO}_{3}\right)_{4}(\mathrm{OH})_{2} \cdot 4 \mathrm{H}_{2} \mathrm{O}\right)$ as an extender in artists' oil paint formulations by Winsor \& Newton (W\&N) [6]. The use of micronized dolomite $\left(\mathrm{CaMg}\left(\mathrm{CO}_{3}\right)_{2}\right)$ as a substitute extender by W\&N is also known [7]. Silvester et al. attributed the formation of epsomite crystals in water sensitive W\&N paints to a reaction between $\mathrm{MgCO}_{3}$ and atmospheric $\mathrm{SO}_{2}$ levels at high relative humidity, where high relative humidity promotes the formation of sulphuric acid $\left(\mathrm{H}_{2} \mathrm{SO}_{4}\right)[4]$.

It was understood that this phenomenon may primarily affect carbonates-of-magnesium containing oil paintings dating from the 1950s to 1970s, which coincided with the global peak of $\mathrm{SO}_{2}$ pollution [8]. Due to a $92 \%$ reduction in $\mathrm{UK} \mathrm{SO}_{2}$ pollution since 1970 [9], atmospheric $\mathrm{SO}_{2}$ levels are now considered negligible, or at least significantly reduced compared to levels in the 1950-70 s, therefore it could be assumed that $\mathrm{MgSO}_{4} \cdot 7 \mathrm{H}_{2} \mathrm{O}$ formation in more recent magnesium carbonate/hydromagnesite/dolomite containing oil paint films would be inhibited.

In particular, the oil paint colours cadmium yellow and French ultramarine have been noted for their disposition to form $\mathrm{MgSO}_{4} \cdot 7 \mathrm{H}_{2} \mathrm{O}$ crystals during artificial ageing [4]. Both cadmium yellow and French ultramarine pigments contain sulphur, present within cadmium sulphide $(\mathrm{CdS})$ and sulphated sodium aluminosilicate $\left(\mathrm{Na}_{8}\left[\mathrm{SiAlO}_{4}\right]_{6} \cdot\left(\mathrm{S}_{3}\right)_{2}\right)$ respectively.

The degradation of cadmium yellow oil paints has been a key area of research due to the observable deterioration associated with this pigment in a number of paintings, including those of notable artists such as Van Gogh [10], Picasso [11] and Matisse [12, 13]. Such degradation may include deterioration of the oil binder and/or reaction of the pigment, resulting in the formation of brown, white, or colourless compounds [11]. Cadmium sulphide is known for its photocatalytic properties [14] which can lead to photodegradation of CdS by oxidation, and formation of cadmium sulphate $\left(\mathrm{CdSO}_{4}\right)$, cadmium carbonate $\left(\mathrm{CdCO}_{3}\right)$ and cadmium oxalate $\left(\mathrm{CdC}_{2} \mathrm{O}_{4}\right)[15,16]$.

Previous investigations into the effect of relative humidity on the photocatalytic properties of CdS identified that photodegradation of CdS-based pigments in oil paints are promoted by a high humidity environment, with photodegradation occurring at $~ 95 \% \mathrm{RH}$ but not at $\sim 45 \% \mathrm{RH}$ [17]. It was reasoned that at higher $\mathrm{RH}$, water more readily permeates the paint film and stabilises radicals formed during photocorrosion of CdS-based pigments [17], and oxidation of the oil binding medium e.g., alkyl, hydroxy, alkoxy, or peroxyl radicals [18]. This reduces the probability of electron-hole recombination thus promoting the photodegradation of CdS [17]. French ultramarine pigments have been shown to be susceptible to framework destruction, an identified cause of fading in ultramarine paints $[19,20]$. Faded pigments have been found to have a reduced concentration of paramagnetic chromophores, i.e., sulphur radical species, $\mathrm{S}_{3}{ }^{-}$as well as an increase in non-framework aluminium species relative to intact blue-coloured pigments. This indicates that fading is caused by framework destruction, accompanied by the release of paramagnetic chromophores. Oxidation of the $\mathrm{S}_{3}{ }^{-}$chromophores into sulphate degradation products is then possible given the high instability of the sulphur radicals once the cage structure has been disrupted [20].

Most recently, ribbon-like crystals have also been observed within age cracks of French ultramarine oil paint of Alexis Mérodack-Jeaneau's La Créole au perroque (1910) [21]. EDX analysis suggested the presence of sodium sulphate. Crystals of similar morphology found on the surface were shown to be deliquescent; this indicates that the occurrence of highly water-soluble sodium sulphate may contribute to water sensitivity in French ultramarine paints. However, it was uncertain whether the identified sodium sulphate had formed as a pigment degradation product or was present as a residual raw material from pigment manufacture i.e., Glauber's salt $\left(\mathrm{Na}_{2} \mathrm{SO}_{4} \cdot 10 \mathrm{H}_{2} \mathrm{O}\right)$ [21-23].

In this study cadmium yellow and French ultramarine Winsor \& Newton artists' oil colour tube paints were used to investigate the influence of light exposure and relative humidity on the formation of epsomite. It was hypothesised that in these paints epsomite crystals can form from the reaction of hydromagnesite and sulphur species arising from pigment degradation [4], and/or from residual sulphate impurities associated with manufacture of $\mathrm{FU}$ or $\mathrm{CY}$ pigments. In this scenario elevated atmospheric $\mathrm{SO}_{2}$ levels would not be required for the formation of epsomite.

\section{Experimental}

\section{Preparation of paint samples}

Paint samples were prepared using W\&N cadmium yellow (CY) PY35, and French ultramarine (FU) PB29, Artists' Oil Colour (AOC) tube paints purchased in 2017. Their composition is reported in the results and discussion section. A Sheen Instruments film caster was used to produce paint films of dimensions $25 \times 10 \mathrm{~cm}$, with a wetfilm thickness of $400 \mu \mathrm{m}$. Paint samples were cast onto a commercially prepared oil-primed linen canvas and an acrylic-emulsion-primed cotton duck canvas (Jackson's Art Supplies, UK). After casting, the paint films were all allowed to cure under ambient laboratory conditions for 3 months, followed by 12 weeks of artificial and natural ageing under the conditions defined in Table 1. 
Table 1 Ageing conditions of paint samples. $C Y=$ cadmium yellow, FU = French Ultramarine

\begin{tabular}{|c|c|c|c|}
\hline \multirow[t]{2}{*}{ Paint } & \multirow[t]{2}{*}{ Substrates } & \multicolumn{2}{|c|}{ Ageing conditions } \\
\hline & & $\begin{array}{l}\text { Relative } \\
\text { humidity (\%) }\end{array}$ & Light conditions \\
\hline \multirow[t]{4}{*}{ CY } & \multirow{4}{*}{$\begin{array}{l}\text { Oil-primed canvas } \\
\text { and acrylic-primed } \\
\text { canvas }\end{array}$} & $\sim 50$ & Ambient light \\
\hline & & $\sim 50$ & Dark \\
\hline & & 75 & $\begin{array}{l}\text { Elevated } \\
\text { light (high lux) }\end{array}$ \\
\hline & & 75 & Near-dark (low lux) \\
\hline \multirow[t]{4}{*}{$\mathrm{FU}$} & \multirow{4}{*}{$\begin{array}{l}\text { Oil-primed canvas } \\
\text { and acrylic-primed } \\
\text { canvas }\end{array}$} & $\sim 50$ & Ambient light \\
\hline & & $\sim 50$ & Dark \\
\hline & & 75 & $\begin{array}{l}\text { Elevated } \\
\text { light (high lux) }\end{array}$ \\
\hline & & 75 & Near-dark (low lux) \\
\hline
\end{tabular}

Control samples were allowed to age within a climatecontrolled conservation studio, with natural daylight passing through UV-filtered glass windows. The temperature and relative humidity of the conservation studio where the samples were housed, was monitored using a Tinytag Ultra data logger which took readings every 15 min over the 12 -week ageing period. The average temperature was $21.5 \pm 0.3{ }^{\circ} \mathrm{C}\left(\max .24 .7{ }^{\circ} \mathrm{C}\right.$; min. $20.8{ }^{\circ} \mathrm{C}$ ), the average humidity was $46.1 \pm 4.8 \% \mathrm{RH}$ ( $\max$. 58.3\% RH; min. 35.1\% RH). Control samples were either exposed to ambient light (max. $200 \mathrm{~lx}$, average of seven readings, measured using a handheld Minolta T10A lux meter) or were loosely wrapped in aluminium foil to achieve darkness. These samples were used as a control in order to evaluate the effect on the development of epsomite of artificial ageing at a high (75\%) RH with elevated light or near-dark conditions, relative to a more typical museum display environment.

Artificial ageing at 75\% RH and elevated light conditions was achieved using a Sanyo MLR-351H environmental chamber fitted with Philips Master TL-D Super $8036 \mathrm{~W} / 840 \mathrm{1SL} / 25$, cool white, $4000 \mathrm{~K}^{\mathrm{bulbs}}{ }^{1}$ with the ultraviolet (UV) component filtered out using polycarbonate filters supplied by Encapsulite, UK. The temperature was set to $25{ }^{\circ} \mathrm{C}$. Conditions inside the Sanyo MLR-351H chamber are controlled and monitored by a built-in sensor and were not additionally monitored using a separate data logger. The chamber temperature and relative humidity was maintained to within $\pm 0.1{ }^{\circ} \mathrm{C}$ and $\pm 3 \%$ RH with respect to their set points of $25^{\circ} \mathrm{C}$,

\footnotetext{
${ }^{1}$ The emission spectra for these bulbs is available in the Philips Product Data Sheet at: https://www.lighting.philips.co.uk/prof/conventional-lamps-andtubes/fluorescent-lamps-and-starters/tl-d/master-tl-d-super-80/9279210840 23_EU/product (accessed 29.07.21).
}

and $75 \% \mathrm{RH}$ respectively. The average illumination inside the chamber was $11,807 \pm 328 \mathrm{~lx}$ (based on an average of three readings, measured using a handheld Minolta T10A lux meter). Ageing at $75 \% \mathrm{RH}$ in near darkness was achieved by placing an opaque tray over the samples which were then placed on a wire rack within the environmental chamber; this reduced the average illumination to $128 \pm 29 \mathrm{~lx}$, (based on an average of three readings using a Minolta T10A lux meter). Reducing the illumination by covering the samples with a large tray was favoured over wrapping in foil in order to ensure adequate air circulation around the paint samples within the environmental chamber, maintaining the correct $\mathrm{RH}$.

\section{Characterisation of paints}

Light microscopy (LM) was undertaken across all samples before and after ageing using a Hirox digital microscope $\mathrm{KH}-8700$. Representative images from different regions of the paint samples were collected at $\times 200$ and $\times 1000$ magnification using lateral lighting to capture surface topography.

Characterisation of paint surfaces using attenuated total reflectance Fourier transform infrared spectroscopy (ATR-FTIR) was conducted before and after ageing using a Thermo Scientific Nicolet iZ10 spectrometer with a germanium attenuated total reflection (ATR) crystal, equipped with a deuterated triglycine sulphate (DTGS) detector. 64 scans were collected at a resolution of $4 \mathrm{~cm}^{-1}$ and the spectral range was from 4000 to $600 \mathrm{~cm}^{-1}$. Three repeat measurements were taken at different positions for each sample. The spectra were then manually baseline corrected and the $\mathrm{CO}_{2}$ absorption was removed using OMNIC 9 software. The repeat spectra were then averaged.

Scanning electron microscopy (SEM) was conducted for selected samples after ageing using a FEI Quanta 650 FEG. Imaging was conducted at $50 \mathrm{~Pa}$ in air. Secondary electron imaging parameters $5 \mathrm{kV}$ voltage and 2.0 spot size were employed, using a working distance of $15 \mathrm{~mm}$. Images were acquired at $\times 2000$ and $\times 4000$ magnification. For energy dispersive $x$-ray spectroscopy (EDX) analysis, the above parameters were used with an increased spot size of 5.5. Elemental maps were acquired for 5 min.

XRD was undertaken of selected samples, before and after ageing using a Bruker D2 Phaser with a copper source. The experiment parameters were set to a spin program for $2 \theta$ values between $10^{\circ}$ and $80^{\circ}$, measured at 0.342 increments. The time step was set at $0.5 \mathrm{~s}$. The patterns were then compared to ICDD powder diffraction database.

XPS was conducted only after ageing using a Thermo Fisher K-Alpha + X-ray Photoelectron Spectrometer 
Table 2 Composition of the W\&N AOC tube paints used

\begin{tabular}{|c|c|c|c|}
\hline \multirow[t]{2}{*}{ Tube paint } & \multirow[t]{2}{*}{ SEM EDX } & \multicolumn{2}{|l|}{ ATR-FTIR (see Figs. 2a, 7a) } \\
\hline & & Absorption bands $\left(\mathrm{cm}^{-1}\right)$ & Assignment \\
\hline \multirow[t]{3}{*}{ Cadmium yellow } & $\mathrm{C}, \mathrm{O}, \mathrm{Cd}, \mathrm{S}, \mathrm{Al}, \mathrm{Mg}, \mathrm{Zn}$ & $\begin{array}{l}3400 \text { [-OH stretch]; } 2924,2854[\mathrm{CH} \text { stretch], } 1740 \\
\text { [ester carbonyl], } 1379\left[\mathrm{CH}_{3} \text { umbrella mode] } 1244\right. \\
{[\mathrm{C}-\mathrm{O} \text { ester]; } 1160[\mathrm{C}-\mathrm{O} \text { ester], } 1100 \text { [C-O ester], } 722} \\
{\left[\mathrm{CH}_{2} \text { rock }\right]}\end{array}$ & Oil \\
\hline & & $\begin{array}{l}3649\left[\mathrm{Mg}(\mathrm{OH})_{2} ; \mathrm{O}-\mathrm{H} \text { vibration }\right] ; 1484,1421 ;\left[\mathrm{CO}_{3}{ }^{2-} /\right. \\
\left.\mathrm{HCO}_{3}{ }^{-} ; \mathrm{v}_{3} \text { asymmetric stretching vibration }\right] 884\left[\mathrm{v}_{2}\right. \\
\text { carbonate], } 853\left[\mathrm{v}_{2} \text { carbonate }\right] 800\left[\mathrm{CO}_{3}{ }^{2-} \text { bending }\right. \\
\text { vibrations] }\end{array}$ & Hydromagnesite \\
\hline & & Broad band at 3400, 1624, 980 & $\begin{array}{l}\text { Possible alumina hydrate (hydrated oxide of } \\
\text { aluminium)? }\end{array}$ \\
\hline \multirow[t]{5}{*}{ French ultramarine } & $\mathrm{C}, \mathrm{O}, \mathrm{K}, \mathrm{Na}, \mathrm{Mg}, \mathrm{Al}, \mathrm{Si}, \mathrm{S}$ & $\begin{array}{l}3340 \text { [-OH stretch]; } 2927,2853 \text { [CH stretch]; } 1740 \\
\text { [ester carbonyl]; } 1162 \text { [C-O ester]; } 1095 \text { [C-O ester] }\end{array}$ & Oil \\
\hline & & $\begin{array}{l}3649,\left[\mathrm{Mg}(\mathrm{OH})_{2} ; \mathrm{O}-\mathrm{H} \text { vibration }\right] ; 3515,3448,1483, \\
1420\left[\mathrm{CO}_{3}{ }^{2-} / \mathrm{HCO}_{3}{ }^{-} \mathrm{v}_{3} \text { asymmetric stretching }\right. \\
\text { vibration }] ; 884\left[\mathrm{v}_{2} \text { carbonate }\right] ; 854\left[\mathrm{v}_{2} \text { carbonate }\right] 800 \\
{\left[\mathrm{CO}_{3}{ }^{2-} \text { bending vibrations }\right]}\end{array}$ & Hydromagnesite \\
\hline & & $\begin{array}{l}\sim 1006 \text { (Si-O-Si asymmetric stretch); 692, } 657 \text { (Si-O } \\
\text { vibrations) }\end{array}$ & Ultramarine \\
\hline & & $\begin{array}{l}3692[\mathrm{Al} \equiv \mathrm{O}-\mathrm{H} \text { stretch], } 3619[\mathrm{OH} \text { stretch]; } 1027 \\
{[\mathrm{Si}-\mathrm{O}-\mathrm{Si}] ; 1006 \text { [Si-O-Si], } 913 \text { [Al-O-H], } 692}\end{array}$ & Probable kaolinite (an aluminosilicate) \\
\hline & & $\begin{array}{l}\text { Broad band at } \sim 3400 \text { (-OH stretch), } 1624 \text { broad } \\
\text { band }\end{array}$ & $\begin{array}{l}\text { Possible alumina hydrate (hydrated oxide of } \\
\text { aluminium)? }\end{array}$ \\
\hline
\end{tabular}

using an aluminium source. The flood gun was enabled to prevent charging. Peak fitting was completed using Thermo Avantage software. Peaks were referenced relative to the $\mathrm{C} 1 \mathrm{~s} \mathrm{C}-\mathrm{C}$ peak at $284.8 \mathrm{eV}$ and normalised before plotting.

An assessment of the water sensitivity of the samples was conducted before and after ageing through manual swab testing using pre-manufactured swabs and deionised water, designed to emulate a traditional surface cleaning process $[2,24]$. Water sensitivity was quantified as the number of swab rolls required to remove pigment and/or binding medium from the paint film [2]. Assessment was repeated three times by the same hand and the results averaged. A lower counted number of swab rolls is indicative of a more sensitive paint surface.

For the SEM, XRD and XPS analysis, approximately $24 \mathrm{~h}$ prior to their characterisation, small portions were cut from the paint samples for analysis. The cut portions did not correlate to areas imaged using LM or those analysed using ATR-FTIR spectroscopy. Thus, separate portions of the paint samples have been imaged and/or analysed for each type of analysis. The general homogeneity of the film-casted paint surfaces enabled comparison of results from the different analytical techniques.

\section{Results and discussion}

\section{Composition of the tube paints}

The composition of the tube paints used in this study were characterised using SEM-EDX (see Table 2, EDX spectra are presented in the Additional file 1: Fig. A1) and ATR-FTIR of control samples aged at 50\% RH/ambient light (Table 2; Fig. 2a and Fig. 7b). ATR-FTIR confirmed the binding medium as oil as expected (Table 2) - safflower oil was specified as the binding medium on the tubes. EDX identified magnesium in both FU and $\mathrm{CY}$ paints consistent with the identification of hydromagnesite extender using ATR-FTIR (Table 2). The presence of aluminium in both the FU and $\mathrm{CY}$ paints may be due to alumina hydrate (hydrated aluminium oxide), often used by W\&N in combination with magnesium carbonate type extenders in artists' oil paint formulations [18]. Kaolinite $\left[\mathrm{Al}_{2} \mathrm{Si}_{2} \mathrm{O}_{5}(\mathrm{OH})\right]$ was identified only in the $\mathrm{FU}$ tube paint using ATR-FTIR (Table 2, Fig. 7a) and XRD (see Additional file 1: Fig. A4). The presence of kaolinite may relate to the use of kaolin (a raw industrial material consisting of fine-grained white clay that is rich in kaolinite [25]) often used in the manufacture of synthetic or French ultramarine, or as an extender [26].

Cadmium and sulphur are consistent with cadmium sulphide $(\mathrm{CdS})$ pigment in the $\mathrm{CY}$ paints; the presence of zinc could however indicate a cadmium zinc sulphide $\left(\mathrm{Cd}_{1-\mathrm{c}} \mathrm{Zn} \mathrm{n}_{\mathrm{c}} \mathrm{S}\right)$ [27]. In the $\mathrm{FU}$ tube paint, the presence of sodium $(\mathrm{Na})$, aluminium $(\mathrm{Al})$, silicon $(\mathrm{Si})$, potassium $(\mathrm{K})$ 
and sulphur (S) and a broad band in the ATR-FTIR spectra at $\sim 1006 \mathrm{~cm}^{-1}$ are consistent with ultramarine pigment, a sulphur-containing sodium aluminium silicate. A broad band centred at $\sim 1620 \mathrm{~cm}^{-1}$ was visible in the $\mathrm{CY}$ sample but not in the FU sample. This could indicate the asymmetric stretching vibrations of amorphous metal carboxylates and/or adsorbed water. Unlike ultramarine, cadmium yellow is known to react to form cadmium carboxylates in oil media [28], and the presence of zinc in the CY paint, raises the possibility of contributions toward the broad band at $\sim 1620 \mathrm{~cm}^{-1}$ from amorphous zinc carboxylates [29].

A summary of key analytical findings for the W\&N AOC CY and FU tube paints is presented in Table 3.

\section{Cadmium yellow}

Light microscopy (LM) did not reveal crystals on the surfaces of CY paint samples aged at $~ 50 \% \mathrm{RH}$ in either light or dark conditions, on either oil-primed or acrylicprimed canvas. Similarly, ATR-FTIR analysis provided no evidence for the formation of sulphate salts in these samples [data not shown]. However as discussed below, surface crystals were visible using LM in CY paints aged at $75 \%$ RH/elevated light (Fig. 1b, c), and a superficial dendritic layer was visible in paints aged at $75 \% \mathrm{RH} /$ near-dark (Fig. 1d). Interestingly the CY paint films aged at $75 \% \mathrm{RH} /$ elevated light prepared on oil-primed canvas presented larger crystals, with an average crystal diameter at the widest point of $41.0 \pm 5.5 \mu \mathrm{m}$, compared to the paint film prepared on acrylic-primed canvas which had an average size of $32.1 \pm 2.0 \mu \mathrm{m}$ (Fig. $1 \mathrm{~b}$ vs. c). However, the smaller crystals on acrylic-primed substrate were more evenly distributed across the surface. This indicates that crystal growth can be influenced by the type of priming, possibly due to differences in absorbency of the primed canvas towards oil binder in the applied paints, which requires further investigation.

ATR-FTIR analysis were consistent with the LM observations-new $\mathrm{SO}_{4}{ }^{2-}$ stretching absorptions at $1087 \mathrm{~cm}^{-1}$ and $\mathrm{SO}_{4}{ }^{2-}$ bending vibrations at $984 \mathrm{~cm}^{-1}$ were seen only on cadmium yellow paints aged at $75 \% \mathrm{RH}$, in both elevated light and near-dark conditions (Fig. 2b, c vs. a). Other new absorption bands seen in paints aged at $75 \%$ $\mathrm{RH}$ were $-\mathrm{OH}$ bands at $\sim 3550,3379$, and 3248 , and an $\mathrm{H}-\mathrm{O}-\mathrm{H}$ bending vibration at $1642 \mathrm{~cm}^{-1}$ likely indicating waters of hydration associated with the sulphate salt.

The diamond and hexagonal morphology of the crystals seen in $\mathrm{CY}$ paint samples aged at $75 \% \mathrm{RH} /$ elevated light (Fig. 1b, c vs. a) is similar to crystals documented on twentieth century oil paintings [30]. SEM-EDX analysis (discussed below) confirmed that the crystals were enriched in sulphur, oxygen, and magnesium, consistent with the formation of magnesium sulphate.
SEM imaging (Fig. 3) of CY paints aged at 75\% RH/ elevated light (Fig. 3a, c-g) show that the surface crystals were located centrally to a superficial non-continuous surface layer that appears in patches across the surface (Fig. 3a). This superficial layer was also enriched in $\mathrm{Mg}, \mathrm{S}$ and $\mathrm{O}$ (Fig. $3 \mathrm{e}-\mathrm{g}$ ) consistent with a $\mathrm{MgSO}_{4}$ salt The observed cracks visible in both defined crystals and superficial layer (Fig. 3c) may be artefacts of the vacuum applied during imaging. The cracks appear similar to those observed by Ruiz-Agudo et al. during thermal dehydration of $\mathrm{MgSO}_{4} \cdot 7 \mathrm{H}_{2} \mathrm{O}$ [31], suggesting that, despite the precautionary low vacuum $(50 \mathrm{~Pa})$ used, the vacuum dehydration of $\mathrm{MgSO}_{4} \cdot 7 \mathrm{H}_{2} \mathrm{O}$ crystals may have contributed to the observed cracking.

A superficial dendritic layer rich in $\mathrm{Mg}$, $\mathrm{S}$, and $\mathrm{O}$ was found on samples aged at 75\% RH/near dark (Fig. 3b) but crystals were absent. This suggests that a superficial $\mathrm{MgSO}_{4}$ surface layer is a precursor to crystal formation, and for $\mathrm{CY}$ oil paint, light likely plays a role in seeding or promoting faster growth of epsomite crystals.

$\mathrm{XRD}$ was used in an attempt to identify the hydration of $\mathrm{MgSO}_{4}$ crystals present on $\mathrm{CY}$ samples aged at $75 \%$ $\mathrm{RH} /$ elevated light. Comparison of the XRD patterns for samples aged at 50\%/ambient light and 75\% RH/elevated lux on oil primed canvas show the CdS pigment to similarly dominate both patterns (Fig. 4). Additional diffraction peaks only observable for the sample aged at $75 \% \mathrm{RH} /$ elevated light were attributed to monoclinic magnesium sulphate hexahydrite, $\mathrm{MgSO}_{4} \cdot 6 \mathrm{H}_{2} \mathrm{O}$, rather than orthorhombic magnesium sulphate heptahydrate $\mathrm{MgSO}_{4} \cdot 7 \mathrm{H}_{2} \mathrm{O}$. However, as the transition between the two crystals occurs below $52.5 \% \mathrm{RH}$ at $25{ }^{\circ} \mathrm{C}$ [32] it is likely that $\mathrm{MgSO}_{4} \cdot 7 \mathrm{H}_{2} \mathrm{O}$ will persist in a high humidity environment and the finding of $\mathrm{MgSO}_{4} \cdot 6 \mathrm{H}_{2} \mathrm{O}$ may be an artefact of $\mathrm{RH}$ or temperature variations during analysis. In a typical museum environment and in accordance with Bizot Green Protocol environmental recommendations [33], it is likely that paintings would experience some fluctuation above and below the 52.5\% RH threshold, hence there may be some reversible transitions occurring around this $\mathrm{RH}$ which may relate to the different rod-, lozenge-, and hexagonal-shaped crystal morphologies documented in the literature $[4,30]$. The relationship between temperature, humidity and crystal morphology is an identified area for further research.

XPS was also carried out on CY samples aged at $\sim 50 \% \mathrm{RH} / \mathrm{ambient}$ light and $75 \% \mathrm{RH}$ /elevated lux on oil primed canvas (Fig. 5). The $\mathrm{C} 1 s$ peaks identify three carbon environments associated with the oil binding medium (Fig. 5a): $\mathrm{C}-\mathrm{C}$ bonds, $\mathrm{C}-\mathrm{O}-\mathrm{C}$ bonds and $\mathrm{C}=\mathrm{O}$ bonds. The absence of a distinct carbonate environment expected from the hydromagnesite extender present in the paint, likely results from relatively low concentrations 


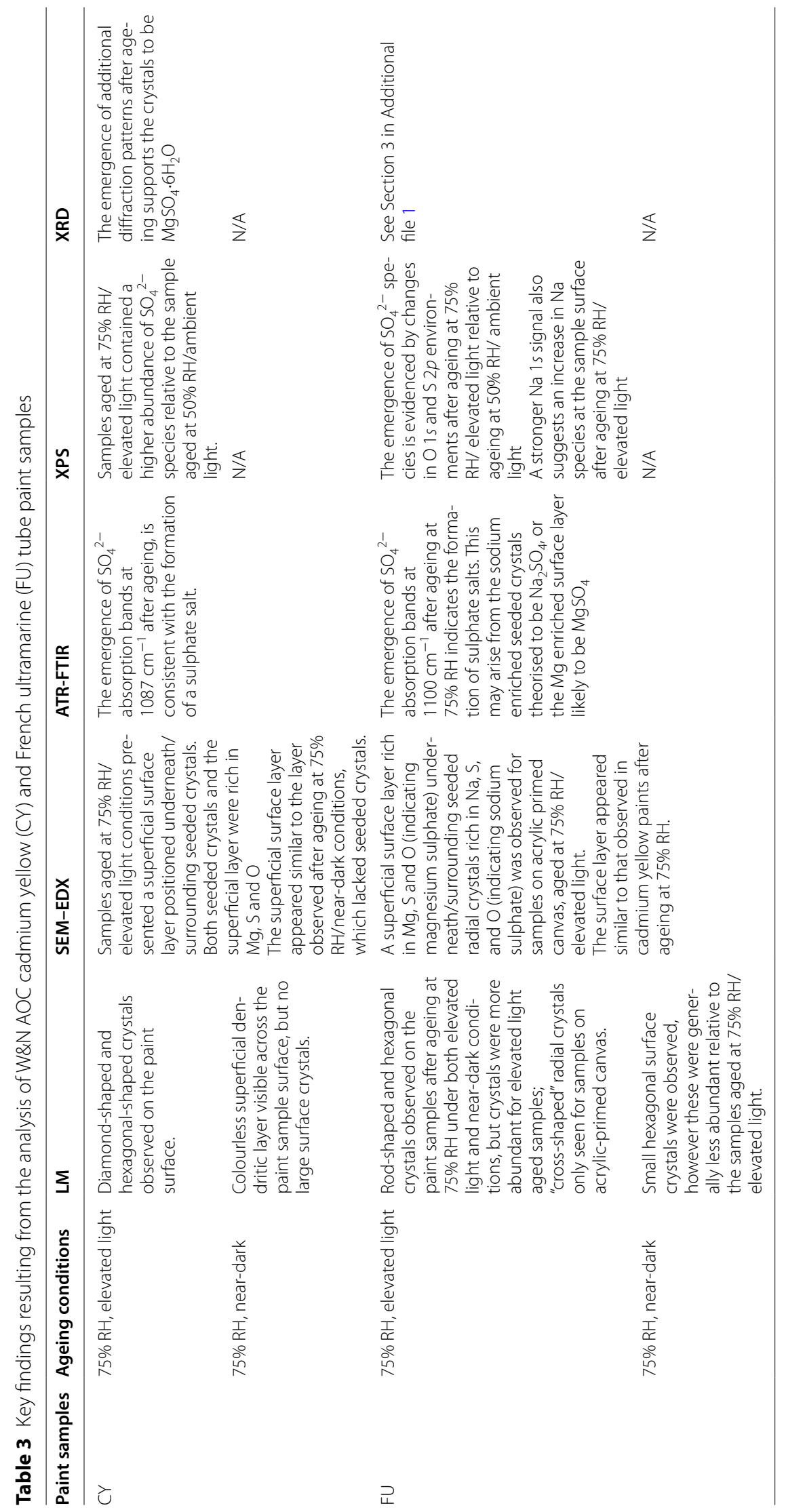



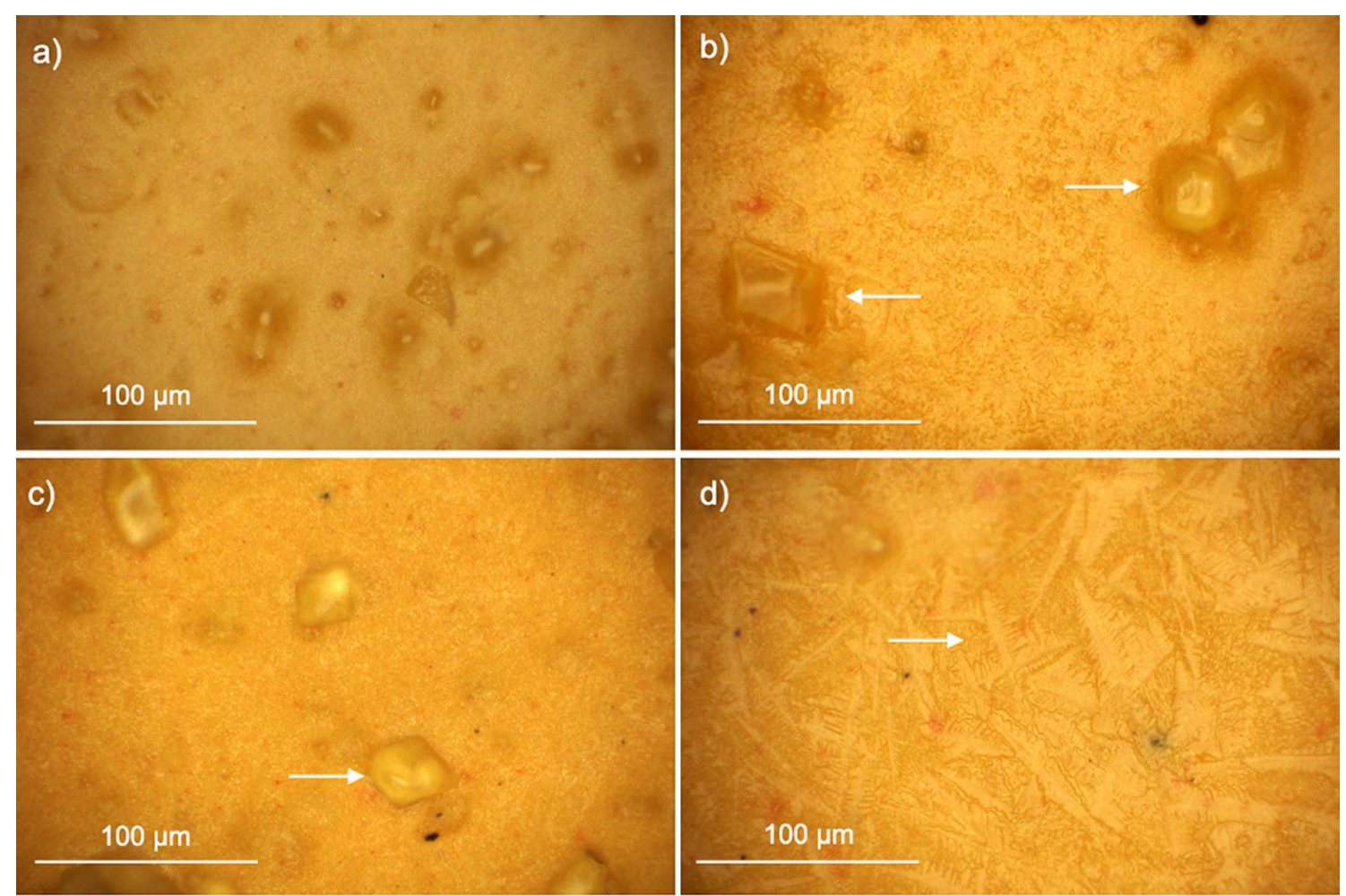

Fig. 1 Light microscopy imaging of W\&N cadmium yellow paint samples under ageing conditions: a 50\% RH, ambient light, oil-primed canvas; b 75\% RH, elevated light conditions, oil-primed canvas; c 75\% RH, elevated light conditions, acrylic-primed canvas; $\mathbf{d} 75 \%$ RH, near-dark conditions, oil-primed canvas

at the surface relative to the oil. Medium rich uppermost surfaces or "medium skins" that contain a lower proportion of pigment and/or extender relative to bulk paint are widely documented for modern oil paints [34]. The $\mathrm{O} 1 s$ peak (Fig. $5 \mathrm{~b}$ ) identifies three different oxygen environments across the two ageing conditions. For samples aged at $\sim 50 \% \mathrm{RH} / \mathrm{ambient}$ light, the oxygen environments are identified as $\mathrm{C}-\mathrm{O}$ and $\mathrm{C}=\mathrm{O}$ at $533.3 \mathrm{eV}$ and $531.9 \mathrm{eV}$ respectively. After ageing at $75 \% \mathrm{RH} /$ elevated lux, an $\mathrm{SO}_{4}{ }^{2-}$ environment emerges at $532.9 \mathrm{eV}$ that is greater relative to the $\mathrm{C}=\mathrm{O}$ environment at $532.2 \mathrm{eV}$, but no $\mathrm{C}-\mathrm{O}$ signal is identified. For samples aged at $75 \% \mathrm{RH} /$ elevated lux, the $\mathrm{S} 2 p$ peak (Fig. $5 \mathrm{~d}$ ) is also considerably less noisy than the equivalent aged at $50 \% \mathrm{RH}$ suggesting a stronger $\mathrm{SO}_{4}{ }^{2-}$ signal. These observations are consistent with the samples aged at $75 \% \mathrm{RH}$ containing a higher abundance of $\mathrm{SO}_{4}{ }^{2-}$ species, which could also be detected using ATR-FTIR, LM, SEM-EDX as described earlier.

With regards the Mg $1 s$ peaks (Fig. $5 \mathrm{c}$ ), a single environment is identified for samples aged at both $50 \%$ and $75 \% \mathrm{RH}$. After ageing at 50\% RH/ambient light, the $\mathrm{Mg}$ environment has a binding energy of $1303.7 \mathrm{eV}$ and is attributed to hydromagnesite, detected using ATR-FTIR.
After ageing at $75 \% \mathrm{RH}$ in elevated light conditions, the $\mathrm{Mg}$ environment shifts to a higher binding energy of $1304.7 \mathrm{eV}$, which likely relates to the conversion of hydromagnesite to $\mathrm{MgSO}_{4}$. The CdS pigment is represented by the $\mathrm{Cd} 3 d$ peaks (Fig. 5e) as identified by the binding energies for the $\mathrm{Cd} 3 \mathrm{~d}_{3 / 2}$ and $3 \mathrm{~d}_{5 / 2}$ which were $412.4 \mathrm{eV}$ and $405.6 \mathrm{eV}$ after ageing at $50 \% \mathrm{RH}$, and $412.7 \mathrm{eV}$ and $405.9 \mathrm{eV}$ after ageing at $75 \% \mathrm{RH}$, respectively. The signal-to-noise ratio is worse for the $75 \% \mathrm{RH} /$ elevated lux sample relative to the $50 \% \mathrm{RH} /$ elevated lux sample. This indicates a change to the $\mathrm{CdS}$ pigment as a result of high $\% \mathrm{RH}$ exposure, which accompanies the formation of $\mathrm{MgSO}_{4} 6 \mathrm{H}_{2} \mathrm{O}$ detected using XRD.

The mechanism for the formation of $\mathrm{MgSO}_{4} \cdot 6-7 \mathrm{H}_{2} \mathrm{O}$ crystals in $\mathrm{CY}$ oil paints containing hydromagnesite and in the absence of elevated $\mathrm{SO}_{2}$ requires further investigation. This may relate to photodegradation of $\mathrm{CdS}$ to form cadmium sulphate, $\mathrm{CdSO}_{4}$, which is promoted by high \% RH $[16,17,35]$. It is possible that the $\mathrm{Cd}$ in $\mathrm{CdSO}_{4}$ may be displaced by $\mathrm{Mg}$ to form $\mathrm{MgSO}_{4}$ due to the higher reactivity of $\mathrm{Mg}$ in the reactivity series. However, this mechanism needs to be investigated to ensure its thermodynamic feasibility. The presence of sulphurous impurities associated with manufacture of the cadmium 
a)
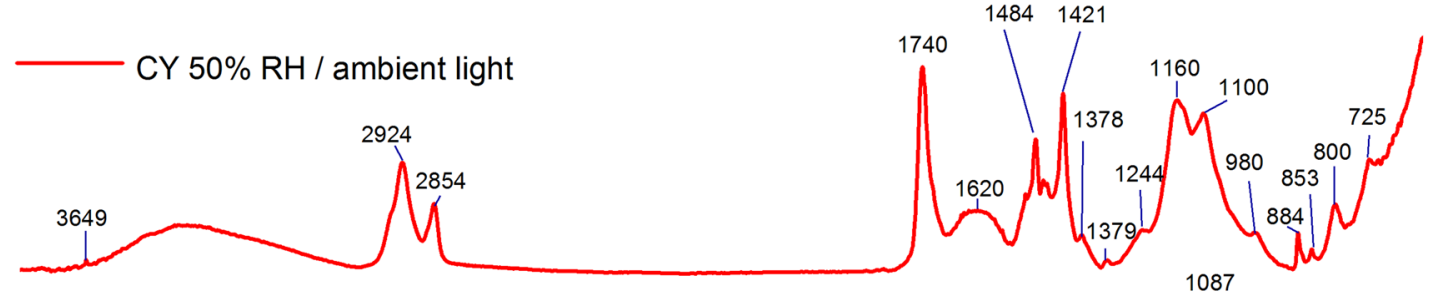

b)
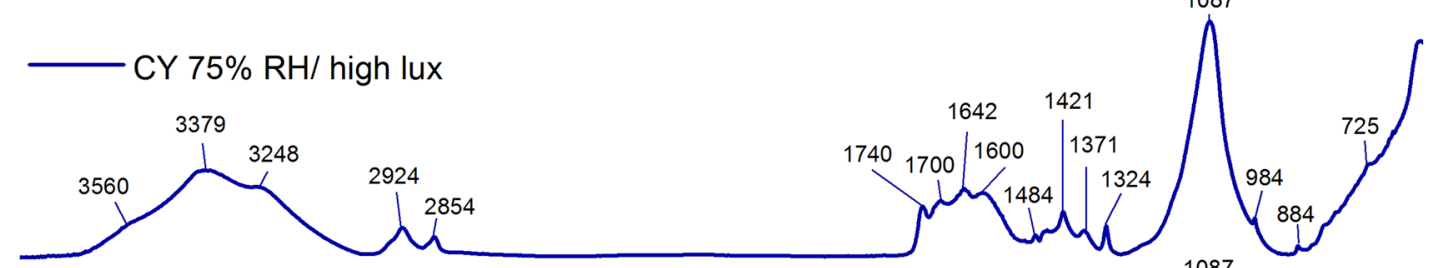

c)

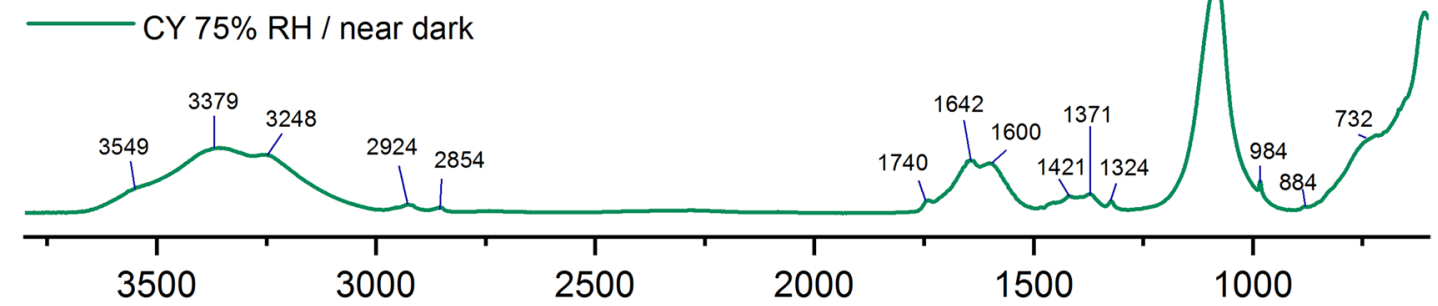

Wavenumber $\left(\mathrm{cm}^{-1}\right)$

Fig. 2 Normalised ATR-FTIR spectra for W\&N cadmium yellow paint samples on oil-primed substrate after ageing conditions a 50\% RH in ambient light conditions; $\mathbf{b} 75 \% \mathrm{RH}$ in elevated light conditions; $\mathbf{c} 75 \% \mathrm{RH}$ in near-dark conditions

sulphide pigments may also be a factor. Cadmium sulphide made using the wet process involves the reaction of a cadmium salt (e.g., cadmium sulphate or others), with a soluble sulphide [17] and hence traces of sulphate containing components could remain in the raw pigment used to make artists' tube paints.

Given the possible relationship between the formation of $\mathrm{MgSO}_{4}$ on the photodegradation of $\mathrm{CdS}$, the observation of a $\mathrm{MgSO}_{4}$ surface layer under near-dark ageing conditions at 75\% RH may seem unexpected (Figs. 1d and $3 \mathrm{~b})$. The light intensity measured in the near-dark aged environment was $\leq 1.1 \pm 0.3 \%$ of the light intensity measured in the elevated light environment and thus significantly reduced relative to the samples exposed to the elevated light levels. However, an average light intensity of $128 \pm 29 \mathrm{~lx}$ was measured, thus photodegradation of CdS may still occur as total darkness was not achieved, especially given that elevated $\mathrm{RH}$ ageing conditions are known to promote oxidation of CdS [16, 17]. Typical museum display conditions are around $200 \mathrm{~lx}$, reduced to $50 \mathrm{~lx}$ for light sensitive works [36]. This suggests that at typical museum light levels, photodegradation of cadmium yellow may still occur. Further research conducted under full dark ageing conditions is required.

\section{French ultramarine}

Surface-disruption and crystal formation were visible using LM for the FU paints on both oil-primed and acrylic-primed canvas aged at $75 \% \mathrm{RH}$ in both light and near-dark conditions, but this was not seen in FU paints aged at $50 \% \mathrm{RH}$ in either light or near-dark conditions (Fig. 6b-d vs a). Consistent with LM observations, ATR-FTIR spectroscopy identified evidence for sulphate salt formation with the emergence of a $\mathrm{SO}_{4}{ }^{2-}$ band at $\sim 1100 \mathrm{~cm}^{-1}$ but only for FU samples aged at $75 \% \mathrm{RH}$ in both elevated light and near-dark conditions (Fig. 7).

As was seen for the CY paints, the choice of priming had an influence on the size and shape of the surface crystals. Of the FU paints aged at $75 \% \mathrm{RH} /$ elevated light, small hexagonal crystals were most abundant at the surface of paints prepared on oil-primed canvas, whilst rod-shaped crystals were significantly more abundant for paints with an acrylic-priming (Fig. $6 \mathrm{~b}$ vs c). The rodshaped crystals also formed radial crystal arrangements, some were typified by three or five branches (not shown) and others appearing 'cross-shaped' (Fig. 6c) with an average crystal length of $24.2 \pm 1.7 \mu \mathrm{m}$. The radial and/ or cross-shaped crystals were only observed on FU paints on acrylic-primed canvas aged at $75 \% \mathrm{RH} /$ elevated light (Fig. 6c), FU paints on oil-primed canvas also aged at $75 \%$ 

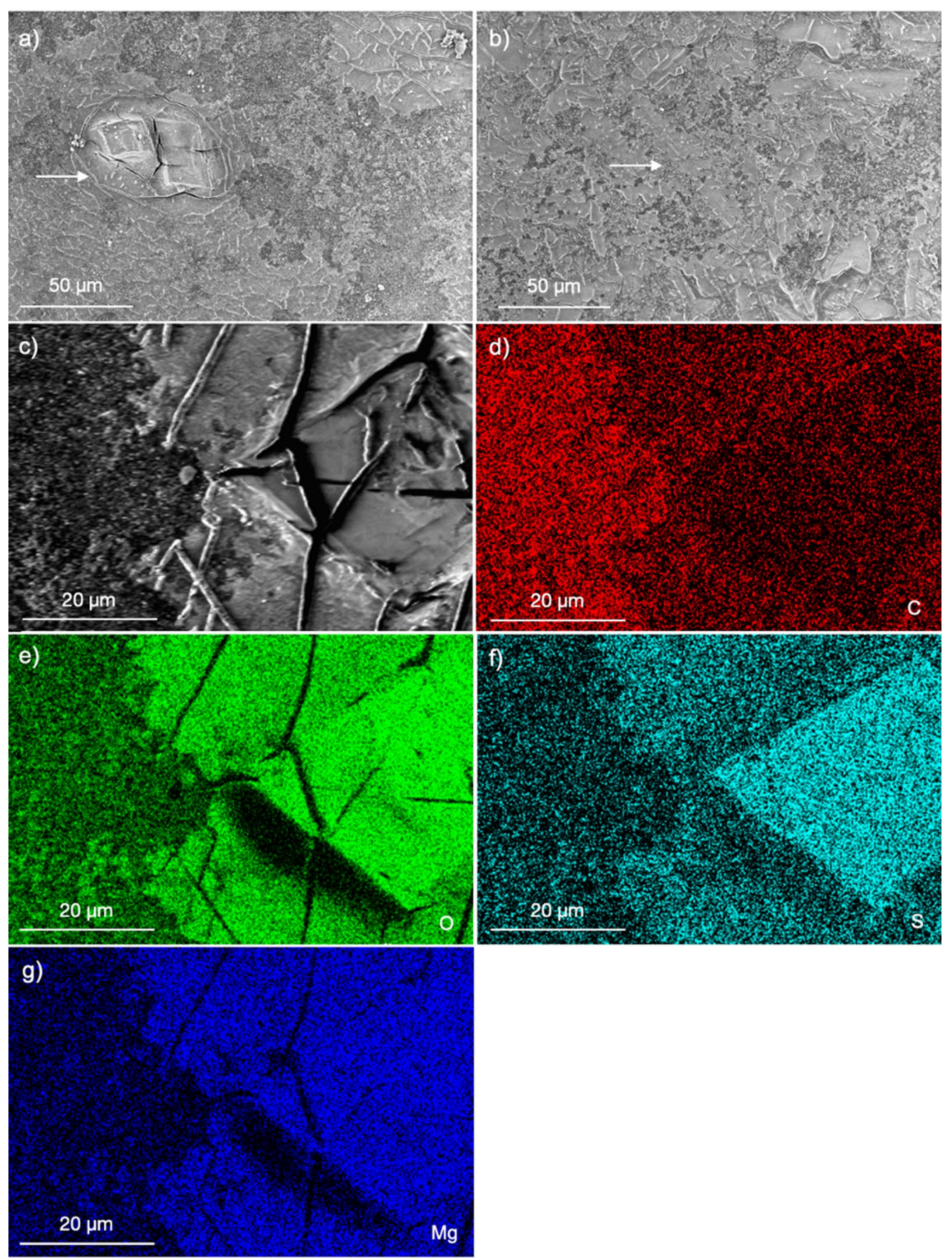

Fig. 3 SEM and EDX imaging of W\&N cadmium yellow paint all aged at 75\% RH and on oil-primed substrate: a Secondary electron (SE) image of sample aged in elevated light conditions; $\mathbf{b}$ SE image of sample aged in near-dark conditions; $\mathbf{c}$ SE image of crystal on surface of sample aged in elevated light conditions; $\mathbf{d}-\mathbf{g}$ false-coloured EDX elemental maps of image $\mathbf{c}$, where red is $\mathrm{C}$, green is $\mathrm{O}$, cyan is $\mathrm{S}$, and blue is $\mathrm{Mg}$

RH/elevated light did not present the cross shaped crystals. FU samples on acrylic-primed canvas aged at $75 \%$ $\mathrm{RH} /$ near-dark conditions only exhibited small hexagonal surface crystals (Fig. 6d), and these were also generally less abundant relative to the FU samples aged at $75 \% \mathrm{RH} /$ elevated light (Fig. 6c, b).

It is possible that nonionic alkylphenol ethoxylate surfactants (APEs) that are likely present in the acrylic emulsion priming [37] but not in the oil priming can 


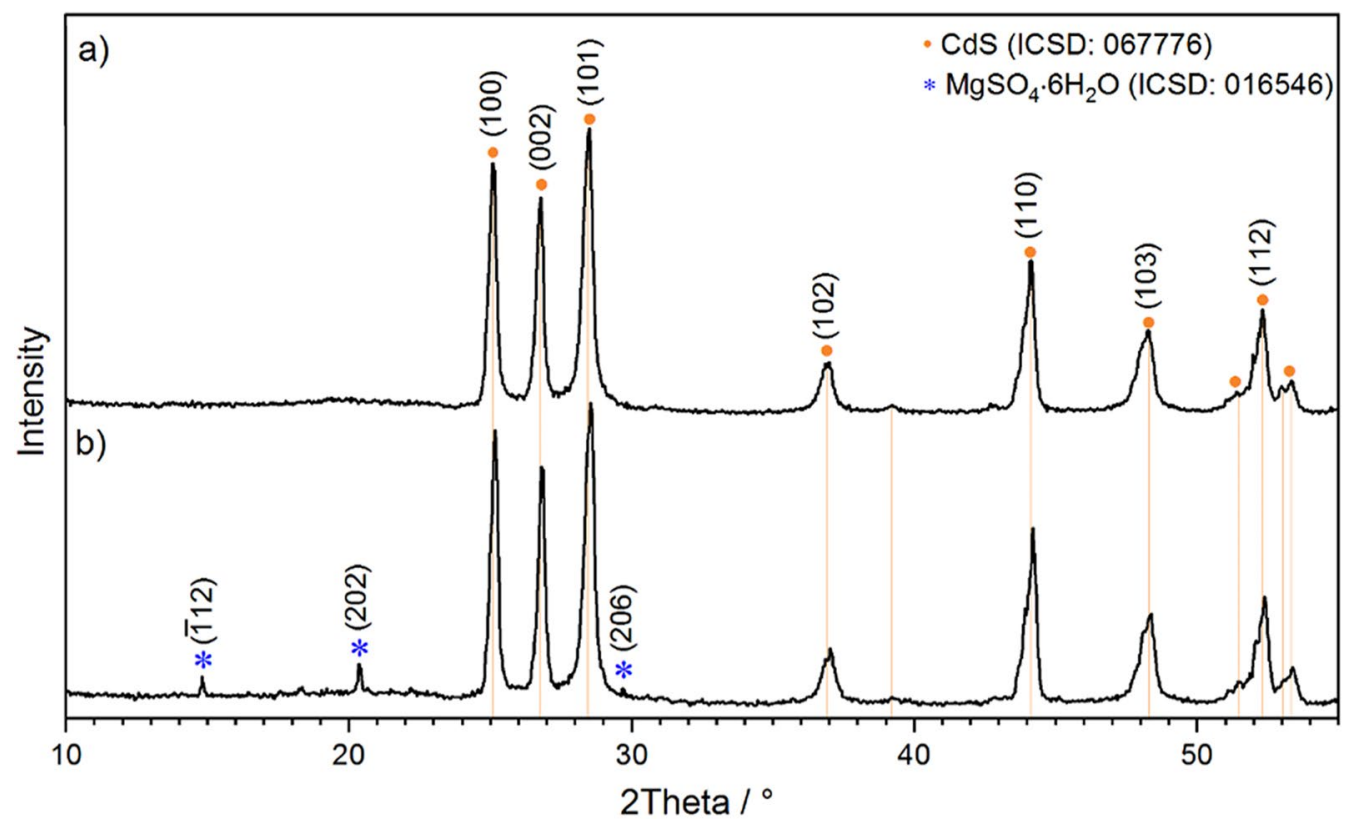

Fig. 4 XRD pattern for W\&N cadmium yellow on oil-primed canvas after ageing at a 50\% RH/ambient light; $\mathbf{b} 75 \%$ RH/elevated light conditions

influence the development metal sulphate salts that may form as a degradation product in susceptible oil paint films. These surfactants could migrate through the paint layer and stabilise the distinctive "crossshaped" radial crystal arrangements [38] however, this requires further investigation.

SEM imaging of the hexagonal and cross-shaped crystals observed in samples aged at 75\% RH/elevated light, revealed a superficial surface layer on paints on both acrylic- and oil-primed canvas (Fig. 8a, b). This superficial surface layer was similar to that seen in the $\mathrm{CY}$ paint films and may correlate with the surface disruption observed using LM on all FU samples aged at $75 \% \mathrm{RH}$.

EDX mapping of a radial arrangement of rod-shaped crystals on the acrylic-primed canvas (Fig. 8c-g) indicated that the crystals are enriched with sulphur and oxygen. Dissimilar to the lozenge-shaped and hexagonal crystals observed in CY paints, the radially arranged rodshaped crystal formations in FU paints appeared depleted in magnesium, but enriched in sodium (Fig. 8f, g). The same was shown for the hexagonal surface crystals in FU [data not shown]. This suggests the surface crystals visible on the $\mathrm{FU}$ paints are sodium sulphate $\left(\mathrm{Na}_{2} \mathrm{SO}_{4}\right)$. XRD was unable to characterise the sodium sulphate salt owing to peaks of interest being of too low intensity (see Additional file 1: Fig A4). The source of the sodium, component of the $\mathrm{Na}_{2} \mathrm{SO}_{4}$ salt is likely to be the French ultramarine pigment, which has an aluminosilicate-sodalite structure where sodium cations counterbalance charges of the $\mathrm{AlO}_{4}^{-1}$ tetrahedra and polysulphide species [20]. In ATR-FTIR spectra, the $\mathrm{Na}_{8}\left[\mathrm{SiAlO}_{4}\right]_{6} \cdot\left(\mathrm{S}_{3}\right)_{2}$ pigment absorption at $\sim 1006 \mathrm{~cm}^{-1}$ appeared reduced after ageing at $75 \% \mathrm{RH}$ relative to samples aged at 50\% RH (Fig. 7). This may indicate a change to the aluminosilicate framework, that can release sulphur radicals from the $\beta$-cage [20]. This could provide a source for the sulphate component of the salts detected, and possibly also the sodium component, however this requires further investigation for example using XANES [20].

Interestingly the superficial surface layer areas directly surrounding the $\mathrm{Na}_{2} \mathrm{SO}_{4}$ crystals were enriched in magnesium, sulphur, and oxygen, suggestive of the $\mathrm{MgSO}_{4}$. This is similar to the surface layer observed in the $\mathrm{CY}$ paints also aged at $75 \% \mathrm{RH} /$ elevated light conditions. The occurrence of a superficial $\mathrm{MgSO}_{4}$ surface layer as distinct from localised surface crystals in FU and $\mathrm{CY}$ oil paints is a novel finding. Due to occurrence of a $\mathrm{MgSO}_{4}$ surface layer coexisting with seeded crystals under light ageing conditions, it is hypothesised that the layer is a precursor for the $\mathrm{MgSO}_{4} \cdot 6-7 \mathrm{H}_{2} \mathrm{O}$ crystal seeding. This is supported by the central positioning of the crystals upon the layer surface which suggests a diffusional influence on seeding and growth of the $\mathrm{MgSO}_{4} \cdot 6-7 \mathrm{H}_{2} \mathrm{O}$ crystals [39]. It is worth noting that the $\mathrm{MgSO}_{4}$ surface layer was not visible under light microscopy for the $\mathrm{CY}$ samples aged at 75\% RH/elevated light (Fig. 1b, c) but rather was detected using SEM-EDX. In current conservation practice the presence of $\mathrm{MgSO}_{4} \cdot 7 \mathrm{H}_{2} \mathrm{O}$ may be identified 


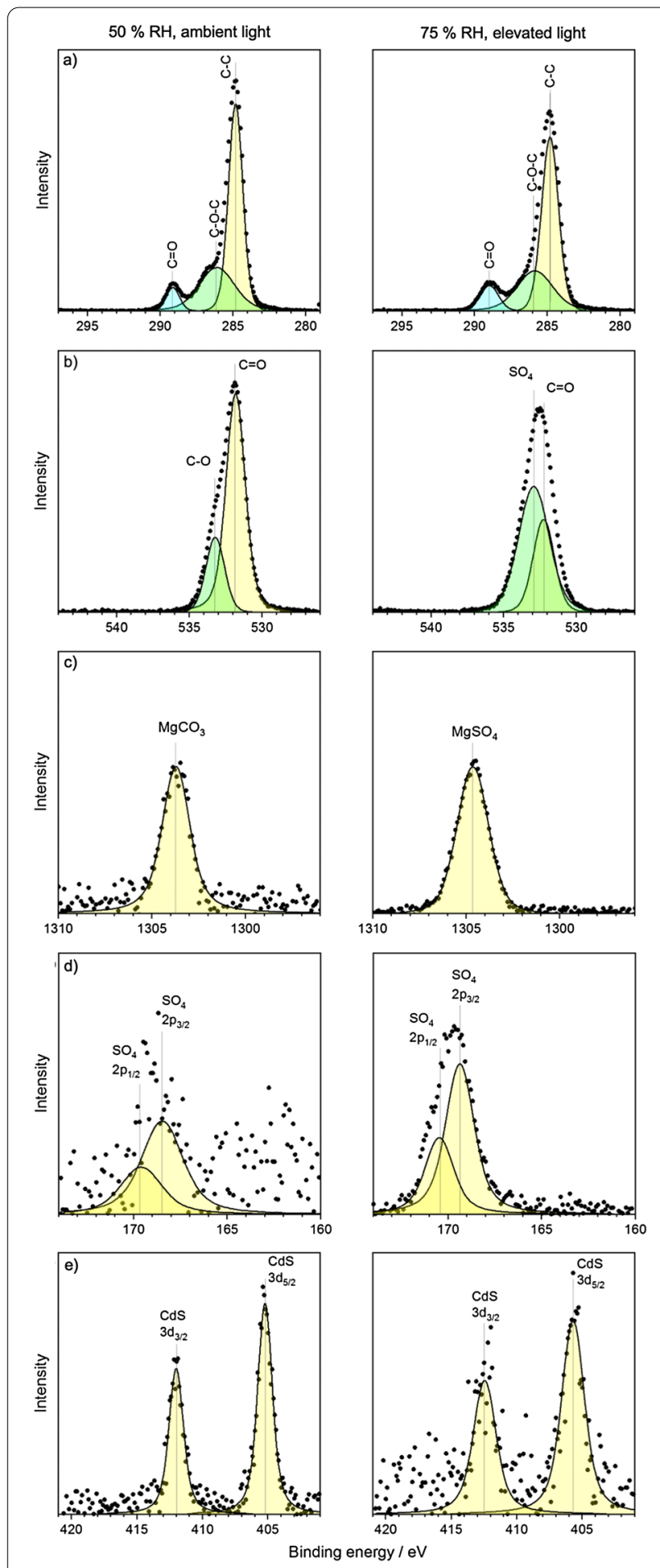

Fig. 5 Normalised XPS spectra for CY paint samples on oil primed canvas aged at 50\% RH and 75\% RH with ambient light and elevated light conditions respectively, left to right, for environments: a C $1 \mathrm{~s} ; \mathbf{b}$ O 1s; c Mg 1s; d S 2p; e Cd $3 d$ in water sensitive oil paintings through the observation of seeded crystal morphologies that, if large enough, may be visible using light microscopy. However, the presence of a superficial $\mathrm{MgSO}_{4}$ surface layer may easily be missed which could explain the absence of documentation of this phenomenon in modern oil paintings.

FU samples aged at 50\% RH/ambient light (no surface crystals) and 75\% RH/elevated light (cross-shaped crystals) were also examined using XPS with the aim of investigating the mechanism of sulphate crystallisation by examining chemical shifts within the paint films.

A new oxygen environment emerged at $532.6 \mathrm{eV}$ after ageing at $75 \% \mathrm{RH}$ in elevated light conditions, likely relating to the $\mathrm{SO}_{4}{ }^{2-}$ group identified using ATR-FTIR in FU samples aged at 75\% RH (Fig. 9b).

The Mg $1 s$ peaks (Fig. 9c) identify as a single environment in each ageing condition. The Mg environment after ageing at 50\% $\mathrm{RH}$ /ambient light has a binding energy of $1304.2 \mathrm{eV}$ consistent with a carbonate environment, most likely hydromagnesite. After ageing at 75\% RH/elevated light, the binding energy of $\mathrm{Mg}$ shifted to $1304.5 \mathrm{eV}$ and was identified as $\mathrm{MgSO}_{4}$.

The $\mathrm{Na} 1 s$ peak (Fig. 9d) after ageing at 75\% RH/elevated light is considerably less noisy than the equivalent aged at 50\% RH/ambient light, suggesting a higher abundance of $\mathrm{Na}$ ions at the sample surface. Ageing at $75 \%$ $\mathrm{RH} /$ elevated light also resulted in a shift relative to ageing at 50\% RH/ambient light, from 1071.5 to $1072.0 \mathrm{eV}$ respectively, although due to the weakness of the signal at $50 \% \mathrm{RH} /$ ambient light, and uncertainty in the peak fit, this shift should be considered as speculative. An S $2 p$ peak could not be identified in the $50 \% \mathrm{RH}$ /ambient light sample, due to the very low abundance of sulphur at the surface (Fig. 9e). However, upon ageing at 75\% RH/elevated light a strong S $2 p$ peak at $169.2 \mathrm{eV}$ was observed, consistent with a metal sulphate signal. This agrees with the ATR-FTIR which indicates the emergence of a $\mathrm{SO}_{4}{ }^{2-}$ stretching absorption at $1100 \mathrm{~cm}^{-1}$ after ageing at $75 \%$ RH/elevated light (Fig. 7b).

Ultramarine pigments are understood to be stable toward light and moisture, however acidic environments can cause disruption to the pigment sodalite cage and result in the release of $\mathrm{S}_{3}{ }^{-}$radical ions [19]. The sulphur radicals are highly reactive and may be oxidised into sulphate compounds once the cage structure has been disrupted. Disruption to the sodalite cage, loss of the sulphur chromophore $\left(\mathrm{S}_{3}{ }^{-}\right)$, and associated fading of synthetic ultramarine pigment have all been documented in twentieth century oil paintings [20]. 

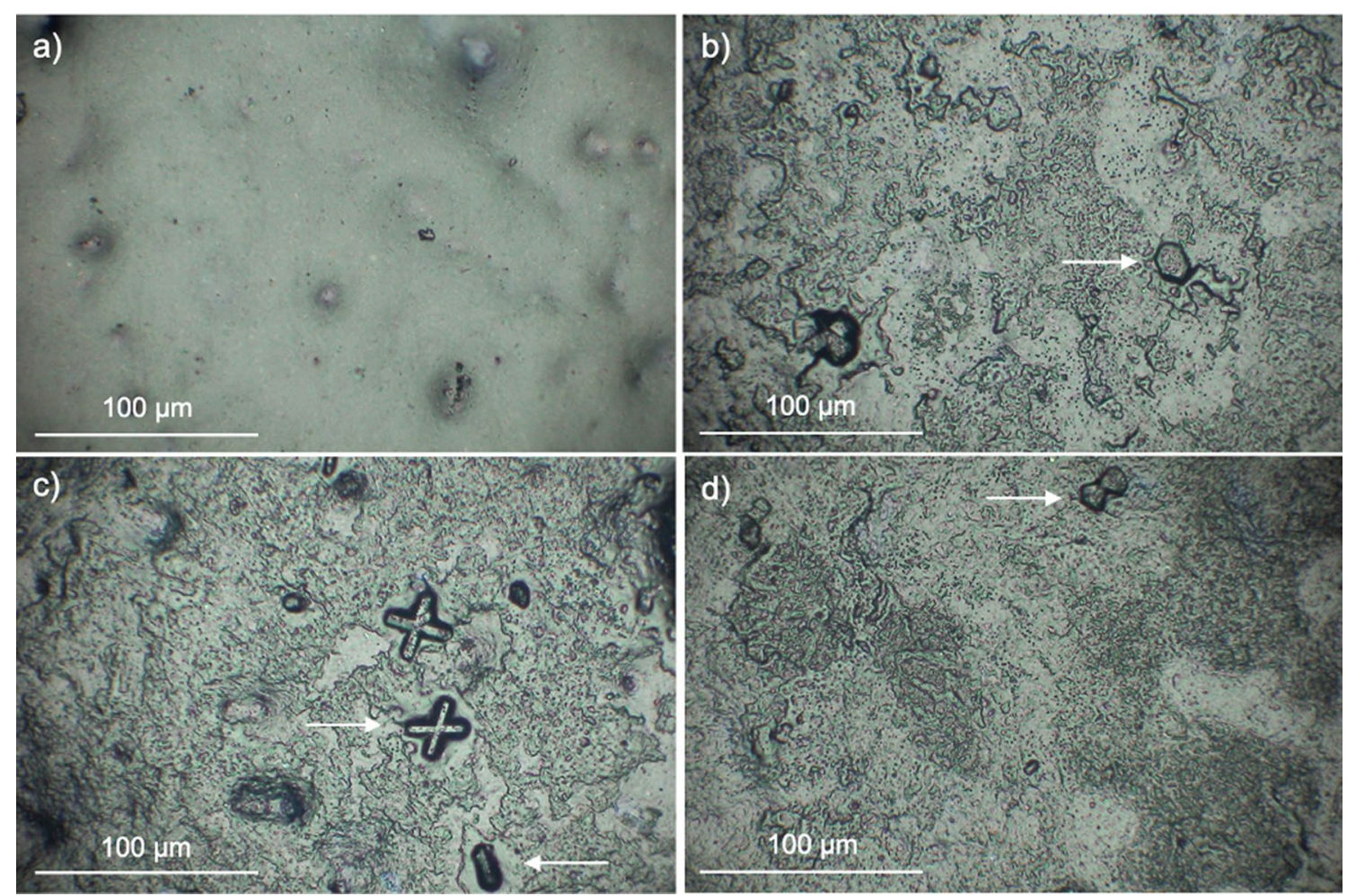

Fig. 6 Light microscopy imaging of W\&N French ultramarine paint samples under ageing conditions: a 50\% RH ambient light, oil-primed canvas; b $75 \%$ RH, elevated light conditions, oil-primed canvas; c 75\% RH, elevated light conditions, acrylic-primed canvas; d 75\% RH, near-dark conditions, acrylic-primed canvas

It is theorised in the case of $\mathrm{FU}$, the $\mathrm{SO}_{4}{ }^{2-}$ group may either originate from impurities/residual materials associated with pigment manufacture or from degradation of the $\mathrm{Na}_{8}\left[\mathrm{SiAlO}_{4}\right]_{6} \cdot\left(\mathrm{S}_{3}\right)_{2}$ pigment. Ultramarine pigment is known for catalysing the oxidative degradation of oil binding media [40], where oxidation and hydrolysis are both promoted at high \% RH [41]. ATR-FTIR results (see Fig. 7) provided evidence for ester hydrolysis for FU samples aged at $75 \% \mathrm{RH}$ relative to $50 \% \mathrm{RH} ; \mathrm{C}-\mathrm{O}$ ester absorptions at 1162 and $1095 \mathrm{~cm}^{-1}$ were no longer visible, and the ester carbonyl band at $1740 \mathrm{~cm}^{-1}$ appears slightly reduced in intensity. It is possible that the oxidative degradation of the binding medium (promoted by both the FU pigment, and high \% RH) leads to an increase in acidity that promotes disruption of the sodalite cage of the ultramarine pigment, leading to the formation of sodium sulphate. Further investigation into the mechanism behind the formation of sodium sulphate and the distribution of $\mathrm{Na}_{2} \mathrm{SO}_{4}$ crystals in $\mathrm{FU}$ oil paint, including potential for formation within bulk paint is required.

\section{Other changes promoted by ageing at elevated $\% \mathrm{RH}$}

For both FU and $\mathrm{CY}$ paints ageing at 75\% RH/elevated light caused a reduction in intensity of the 1483 band relative to the $1421 \mathrm{~cm}^{-1}$ infrared bands (Fig. 2 and Fig. 7). This has been reported before for W\&N oil paints aged under a tropical rainforest climate of $78-90 \% \mathrm{RH}$, and temperatures from 23.2 to $26.2{ }^{\circ} \mathrm{C}$ [42], and has been observed by the authors in numerous naturally aged W\&N AOC paint swatches.

It is possible that the changes to the 1483, and $1421 \mathrm{~cm}^{-1}$ bands indicate changes to the two $\mathrm{CO}_{3}{ }^{2-}$ environments of hydromagnesite that accompany the conversion to magnesium sulphate salts, however further investigation is required.

For both FU and CY paints, ATR-FTIR spectra provided evidence for ester hydrolysis promoted by ageing at $75 \% \mathrm{RH}$, with reduction in the intensity of the ester carbonyl band at $1740 \mathrm{~cm}^{-1}$ observed for both paints, but particularly so for $\mathrm{CY}$ (Figs. 2 and 7). Oxidation and hydrolysis are promoted by high relative humidity [41]. For FU paints a new broad absorption centred at $\sim 1600 \mathrm{~cm}^{-1}$ was seen after ageing at $75 \%$ RH (Fig. 7) possibly indicating the formation of amorphous metal carboxylates. 


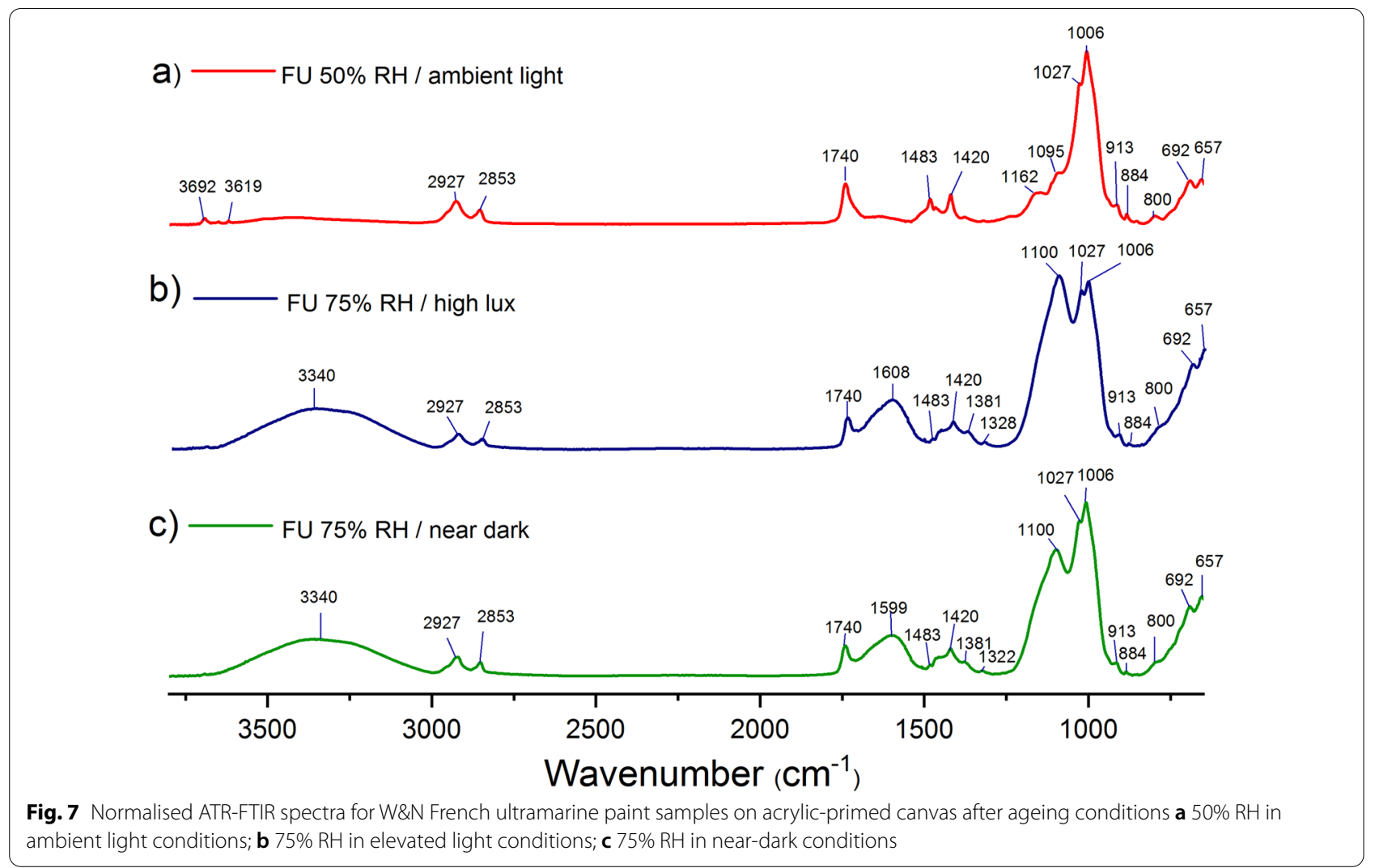

\section{Water sensitivity}

Swab rolling tests were carried out for tube paint samples to explore the relationship between environmental conditions, sulphate salt formation, and assessed water sensitivity. A lower number of swab rolls indicates a more sensitive paint film as evidenced via pigment pickup. The results indicate that for both the $\mathrm{CY}$ and FU paints, ageing under high relative humidity, which promoted the formation of magnesium sulphate salts (as indicated by the ATR-FTIR, SEM-EDX and XPS results), produced the most water sensitive paints [43] (Fig. 10a, b). Since ester hydrolysis (indicated in this study by ATR-FTIR) and oxidation of the oil binding medium are promoted by the high RH conditions [41] it is likely that the condition of the binding medium is also contributing toward the observed paint sensitivity [18].

\section{Conclusions and further work}

This investigation demonstrated that $\mathrm{MgSO}_{4} \cdot 6-7 \mathrm{H}_{2} \mathrm{O}$ can form as a surface layer and/or as surface crystals in hydromagnesite-containing $\mathrm{CY}$ and $\mathrm{FU}$ artists oil paint films in the absence of elevated $\mathrm{SO}_{2}$. Elevated light and relative humidity also appear to promote the formation of sodium sulphate $\left(\mathrm{Na}_{2} \mathrm{SO}_{4}\right)$ crystals in $\mathrm{FU}$ oil paint. The formation of $\mathrm{SO}_{4}{ }^{2-}$ crystals, in both $\mathrm{CY}$ and $\mathrm{FU}$ oil paints is promoted by high relative humidity $(75 \% \mathrm{RH})$ relative to lower relative humidity conditions $(50 \% \mathrm{RH})$. Furthermore, light in combination with high relative humidity promotes crystal seeding and growth. These soluble salt formations were associated with an increase in observed water sensitivity of the paint films, but the condition of the binding medium is a likely contributing factor to the observed paint sensitivity.

The sulphate component of the salts identified in this study may originate from the degradation of the $\mathrm{CY}$ and FU pigments. The photodegradation of $\mathrm{CdS}$ into products including $\mathrm{CdSO}_{4}$ is well known. However, further study could be directed to investigate the degradation behaviour of $\mathrm{Na}_{8}\left[\mathrm{SiAlO}_{4}\right]_{6} \cdot\left(\mathrm{S}_{3}\right)_{2}$ in modern $\mathrm{FU}$ oil paints, including the mechanism and localisation of $\mathrm{Na}_{2} \mathrm{SO}_{4}$ formation.

This finding broadens the scope of paintings potentially vulnerable to soluble $\mathrm{SO}_{4}{ }^{2-}$ crystal formation, which extends to all containing $\mathrm{CY}$ and $\mathrm{FU}$ unvarnished modern oil paints extended with hydromagnesite, particularly if exposed to high (75\%) RH. Further research is also required to study the influence of exposure to $\mathrm{RH}$ ranging between 50 and $75 \% \mathrm{RH}$. It is also acknowledged that in this study ambient sulphur dioxide levels were not measured, and hence the potential influence 

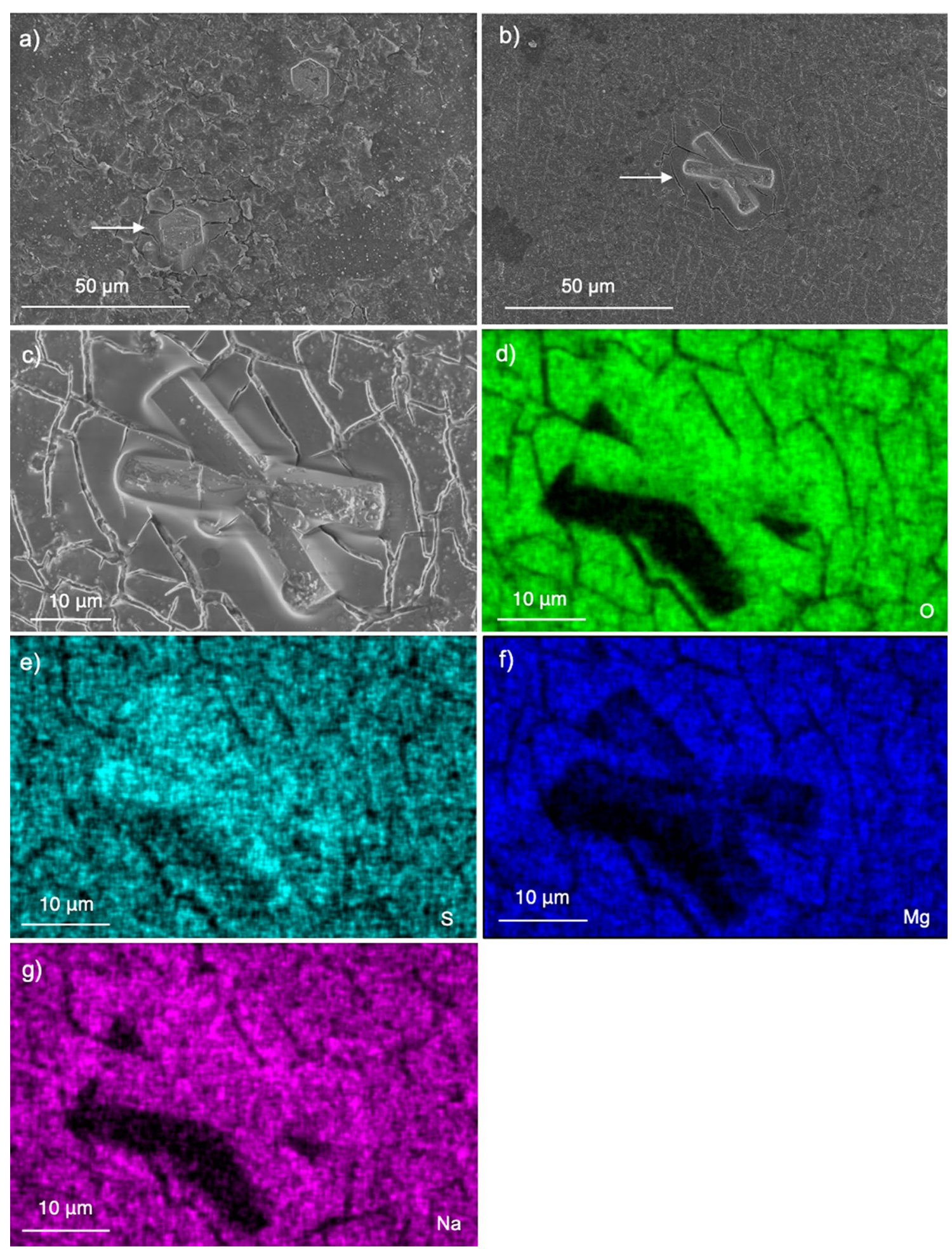

Fig. 8 SEM and EDX imaging of W\&N French ultramarine paint aged at 75\% RH, in elevated light conditions: a SE image on oil-primed canvas; $\mathbf{b}$ SE image on acrylic-primed canvas; $\mathbf{c}$ SE image of crystal on surface on acrylic-primed surface; $\mathbf{d}-\mathbf{g}$ false-coloured EDX elemental maps of image $\mathbf{c}$ whereby green is $\mathrm{O}$, cyan is $\mathrm{S}$, blue is $\mathrm{Mg}$, and magenta is $\mathrm{Na}$ 


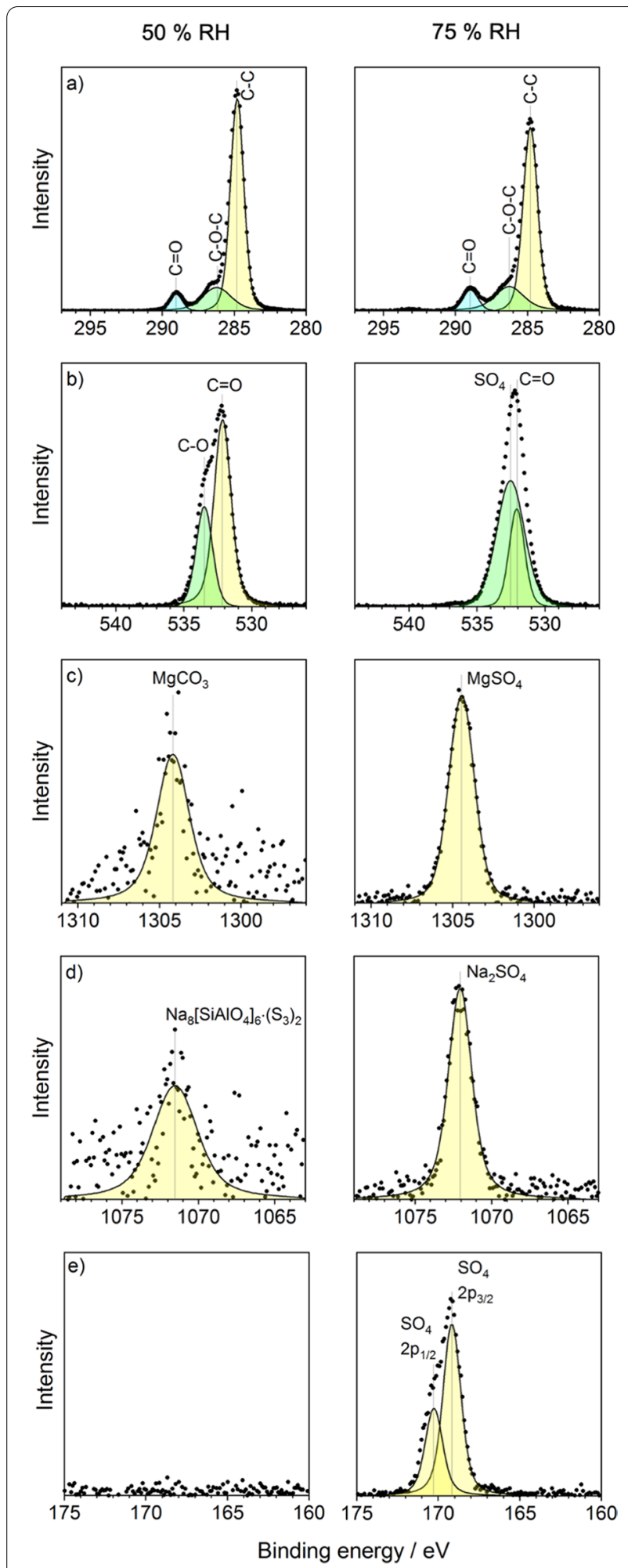

Fig. 9 Normalised XPS spectra for W\&N French ultramarine paint samples on acrylic-primed canvas aged at 50\% RH and 75\% RH with ambient light and elevated light conditions respectively, left to right, for environments: a C 1s; b O 1s; c Mg 1s; d Na 1s; and e S $2 p$ a)

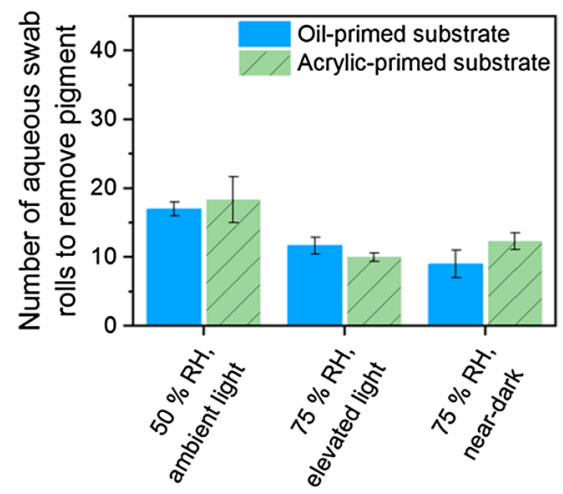

b)

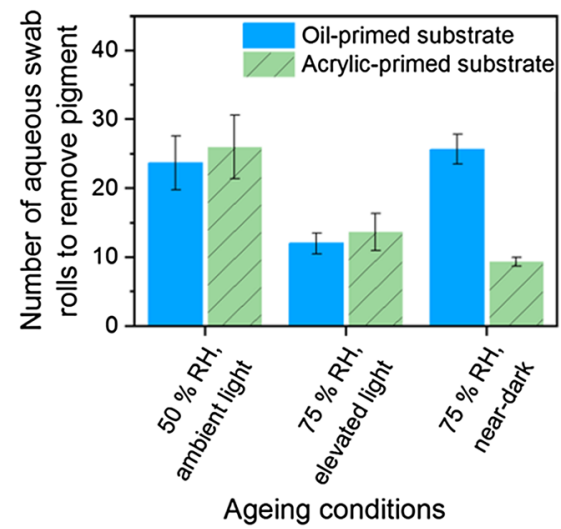

Fig. 10 Number of aqueous swab rolls required to remove pigment for CY samples (a) and FU samples (b), after ageing. A low number of swab rolls indicates high water sensitivity

of low levels of $\mathrm{SO}_{2}$ expected in an indoor environment was not evaluated. This is an area that merits further investigation. Future studies would usefully investigate critical environmental thresholds leading to pigment degradation and the development of epsomite and crystal formation, as well as the effect of fluctuating temperature and relative humidity conditions. The factors influencing crystal shape, morphology and composition (i.e., surface layer, rod-, lozenge-, cross-shaped crystals), including the effect of the choice of substrate, the process of $\mathrm{MgSO}_{4}$ surface layer formation, and the relationship of these salts to the development of water sensitivity all merit further study. It is well known that light exposure and raised and/or fluctuating relative humidity are factors amongst others, that promote ageing and degradation of oil paintings. This research does however highlight the importance of minimising exposure to light and raised relative humidity for paintings with $\mathrm{CY}$ and FU oil paint passages containing hydromagnesite extender, in order to help slow down the formation of water-soluble salts which contribute toward the development of water-sensitive paint passages. 


\section{Abbreviations}

RH: Relative humidity; W\&N: Winsor \& Newton; CY: Cadmium yellow; FU: French ultramarine.

\section{Supplementary Information}

The online version contains supplementary material available at https://doi. org/10.1186/s40494-021-00569-2.

Additional file 1: Figure A1. Photographs of W\&N AOC cadmium yellow and French ultramarine tube paint samples. Figure A2. EDX spectrum for W\&N Cadmium Yellow tube paint. Figure A3. EDX spectrum for W\&N French Ultramarine tube paint. Figure A4. XRD pattern for W\&N AOC French ultramarine on acrylic-primed canvas.

\section{Acknowledgements}

The authors would also like to thank colleagues at Imperial College London who offered their time and expertise; Dr Mahmoud Ardakani for his help in facilitating VP SEM imaging, and Dr Gwilherm Kerherve for his knowledge and guidance regarding XPS measurements. With thanks also to Dr Alex Ball, Natural History Museum, London for facilitating VP SEM imaging.

\section{Authors' contributions}

$\mathrm{JH}$ collected and analysed experimental data and was a major contributor in writing the manuscript. $J \mathrm{~L}$ co-developed the project, interpreted experimental data and was also a major contributor in writing the manuscript. BAO and DJP co-developed and monitored the project and edited the manuscript. All authors read and approved the final manuscript.

\section{Funding}

This research was undertaken at Tate, London, in collaboration with Imperial College London. This research was carried out without any funding.

\section{Availability of data and materials}

The datasets used and/or analysed during the current study are available from the corresponding author on reasonable request.

\section{Declarations}

\section{Ethics approval and consent to participate}

Not applicable.

\section{Consent for publication}

Not applicable.

\section{Competing interests}

The authors declare that they have no competing interests.

\section{Author details}

${ }^{1}$ Department of Materials, Imperial College London, Exhibition Road, London SW7 2AZ, UK. ${ }^{2}$ Conservation Department, Tate, Millbank, London SW1P 4RG, UK. ${ }^{3}$ Research Complex at Harwell, Harwell Science and Innovation Campus, Didcot, Oxfordshire OX11 OFA, UK.

Received: 4 May 2021 Accepted: 2 August 2021

Published online: 06 September 2021

\section{References}

1. Burnstock A, van den Berg KJ, de Groot S, Wijnberg L. An investigation of water-sensitive oil paints in twentieth-century painting. In: Learner T, Smithen P, Krueger J, Schilling M, editors. Modern paints uncovered. Los Angeles: Getty Conservation Institute; 2006. p. 177-88.

2. Mills L, Burnstock A, Duarte F, de Groot S, Megens L, Bisschoff M, van Keulen $\mathrm{H}$, van den Berg KJ. Water sensitivity of modern artists' oil paints.
In: ICOM Committee for Conservation 15th Triennial Meeting New Delhi India 22-26 September 2008, Allied Publishers, p. 651-659.

3. Tempest H, Burnstock A, Saltmarsh P, van den Berg KJ. Sensitivity of oil paint surfaces to aqueous and other solvents. In: Mecklenburg M, Charola E, Koestler R, editors. New Insights into the Cleaning of Paintings: Proceedings from the Cleaning 2010 International Conference Universidad Politecnica de Valencia and Museum Conservation Institute, 2010 p. 107-14.

4. Silvester G, Burnstock A, Megens L, Learner T, Chiari G, van den Berg KJ. A cause of water-sensitivity in modern oil paint films: the formation of magnesium sulphate. Studies in Conservation. 2014;59(1):38-51.

5. Soldano A, van den Berg KJ. Investigation into the surface conductivity of water-sensitive modern oil paints. In: van den Berg KJ, de Keijzer M, de Tagle A, Krueger J, Heydenreich G, Burnstock A, Learner T, editors. Issues in contemporary oil paint. Springer: Berlin; 2014. p. 407-17.

6. Helwig K, Moffatt EA, Corbeil M-C, Duguay D. Early twentieth-century artists paints in Toronto: archival and material evidence. Journal of the Canadian Association for Conservation, 2015;40:19-34.

7. Cooper A, Burnstock A, van den Berg KJ, Ormsby B. Water sensitive oil paints in the twentieth century: a study of the distribution of watersoluble degradation products in modern oil paint films. In: van den Berg KJ, de Keijzer M, de Tagle A, Krueger J, Heydenreich G, Burnstock A, Learner T, editors. Issues in contemporary oil paint. Springer: Berlin; 2014. p. 295-310.

8. Smith SJ, Van Aardenne J, Klimont Z, Andres RJ, Volke A, Arias SD. Anthropogenic sulfur dioxide emissions: 1850-2005. Atmos Chem Phys. 2011;11(3):1101-16.

9. Murrells TP et al. "Report: UK Emissions of Air Pollutants 1970 to 2008", 2010, UK AIR, Air Information Resource, https://uk-air.defra.gov.uk/library/ reports?report_id=621. Accessed 6 Aug 2021.

10. Van der Snickt G, Janssens K, Dik J, De NolfW, Vanmeert F, Jaroszewicz J, Cotte M, Falkenberg G, Van der Loeff L. Combined use of synchrotron radiation based micro-X-ray fluorescence, micro-X-ray diffraction, micro-X-ray absorption near-edge, and micro-fourier transform infrared spectroscopies for revealing an alternative degradation pathway of the pigment cadmium yellow in a painting by Van Gogh. Anal Chem. 2012;84(23):10221-8. https://doi.org/10.1021/ac3015627.

11. Leone B, Burnstock A, Jones C, Hallebeek P, Boon JJ, Keune K. The deterioration of cadmium sulphide yellow artists' pigments. In: 14th Trienn Meet Hague, 12-16 September 2005 Prepr, ICOM Comm Conserv, 2005; 20(1914), pp. 803-13.

12. Mass J, Sedlmair J, Patterson CS, Carson D, Buckley B, Hirschmugl C. SR-FTIR imaging of the altered cadmium sulfide yellow paints in Henri Matisse's le Bonheur de vivre (1905-6) —examination of visually distinct degradation regions. Analyst. 2013;138(20):6032-43.

13. Pouyet $E$, et al. $2 D X$-ray and FTIR micro-analysis of the degradation of cadmium yellow pigment in paintings of Henri Matisse. Appl Phys A Mater Sci Process. 2015;121(3):967-80.

14. Boakye F, Nusenu D. The energy band gap of cadmium sulphide. Solid State Commun. 1997;102(4):323-6.

15. Williams R. Becquerel photovoltaic effect in binary compounds. J Chem Phys. 1960;32(5):1505-14.

16. Monico L, et al. Probing the chemistry of CdS paints in the Scream by in situ noninvasive spectroscopies and synchrotron radiation $\mathrm{x}$-ray techniques. Sci Adv. 2020;6(20):1-12.

17. Monico $\mathrm{L}$, et al. Role of the relative humidity and the $\mathrm{Cd} / \mathrm{Zn}$ stoichiometry in the photooxidation process of cadmium yellows (CdS/Cd1-xZnxS) in oil paintings. Chemistry. 2018;45:11584-93.

18. Bonaduce I, Duce C, Lluveras-Tenorio A, Lee J, Ormsby B, Burnstock A, van den Berg KJ. Conservation issues of modern oil paintings: a molecular model on paint curing. Acc Chem Res. 2019;52(12):3397-406.

19. Del Federico E, Shöfberfer W, Schelvis J, Kapetanaki S, Tyne L, Jerschow A. Insight into framework destruction in ultramarine pigments. Inorg Chem. 2006:45(3):1270-6.

20. Cato E, Borca C, Huthwelker T, Ferreira ESB. Aluminium X-ray absorption near-edge spectroscopy analysis of discoloured ultramarine blue in 20th century oil paintings. Microchem J. 2016;126:18-24.

21. Graczyk A, Hélou-de La Grandière P, Phenix A, Mirabaud S. Oil paint straight from the tube: paint-specific deterioration in works by Alexis Mérodack-Jeaneau, 1910-1913. In: van den Berg KJ, Bonaduce I, 
Burnstock A, Ormsby B, Scharff M, Carlyle L, Heydenreich G, Keune K, editors. Conservation of modern oil paintings. Springer: Berlin; 2019. p. 229-43.

22. Plesters J. Ultramarine blue natural and artificial. Washington, DC: National Gallery of Art; 1993.

23. Doerner M. The materials of the artist and their use in painting. New York: Harcourt Brace International; 1934

24. Chung JY, Ormsby B, Lee J, Burnstock A, van den Berg KJ. An investigation of options for surface cleaning unvarnished water-sensitive oil paints based on recent developments for acrylic paints. ICOM-CC 18th Trienn Conf Prepr. 2017.

25. Prasad MS, Reid KJ, Murray HH. Kaolin: processing, properties and applications. Appl Clay Sci. 1991;6(2):87-119.

26. Kajinebaf $\mathrm{V}$, Rezaeian F, Rajabi M, Baghshahi S. Replacing nano-clay for kaolin in ultramarine pigments. Pigment Resin Technol. 2014;43(1):1-7.

27. Rosi F, et al. UV-Vis-NIR and micro Raman spectroscopies for the non destructive identification of $\mathrm{Cd} 1-\times \mathrm{Zn} \times \mathrm{S}$ solid solutions in cadmium yellow pigments. Microchem J. 2016;124:856-67.

28. Mazzeo R, Prati S, Quaranta M, Joseph E, Kendix E, Galeotti M. Attenuated total reflection micro FTIR characterisation of pigment-binder interaction in reconstructed paint films. Anal Bioanal Chem. 2008;392:65-76.

29. Hermans JJ, Keune K, van Loon A, ledema PD. An infrared spectroscopic study of the nature of zinc carboxylates in oil paintings. J Anal At Spectrom. 2015:30:1600-8.

30. Bay L, Burnstock A, Lee J, Ormsby B, van den Berg KJ. Water sensitivity of modern oil paintings. ICOM-CC 18th Trienn Conf Prepr Copenhagen. 4-8 September 2017; p. 1302

31. Ruiz-Agudo E, Martin-Ramos JD, Rodriguez-Navarro C. Mechanism and kinetics of dehydration of epsomite crystals formed in the presence of organic additives. J Phys Chem B. 2007;111(1):41-52.

32. Steiger $M$, Linnow K, Ehrhardt $D$, Rohde M. Decomposition reactions of magnesium sulfate hydrates and phase equilibria in the $\mathrm{MgSO}_{4}-\mathrm{H}_{2} \mathrm{O}$ and $\mathrm{Na}^{+}, \mathrm{Mg}^{2+}, \mathrm{Cl}^{-}, \mathrm{SO}_{4}^{2-}, \mathrm{H}_{2} \mathrm{O}$ systems with implications for Mars. Geochim Cosmochim Acta. 2011;75(12):3600-26.

33. ICOM-CC. Environmental guidelines ICOM-CC and IIC declaration. 2014. http://www.icom-cc.org/332/-icom-cc-documents/declaration-on-envir onmental-guidelines/\#.X8Dily2I2L1. Accessed 27 Nov 2020.

34. Burnstock A, van den Berg KJ, Twentieth century oil paint. The interface between science and conservation and the challenges for modern oil paint research. In van den Berg KJ, de Keijzer M, de Tagle
A, Krueger J, Heydenreich G, Burnstock A, Learner T, editors. Issues in contemporary oil paint. Springer: Berlin; 2014. https://doi.org/10.1007/ 978-3-319-10100-2_1.

35. Davis AP, Huang CP. The photocatalytic oxidation of sulfur-containing organic compounds using cadmium sulfide and the effect on CdS photocorrosion. Water Res. 1991;25(10):1273-8.

36. Stolow N. Procedures and conservation standards for museum collections in transit and on exhibition. Paris: UNESCO; 1981.

37. Di Crescenzo M, Zendri E, Rosi F, Miliani C. A preliminary FTIR-based exploration of the surfactant phase separation process in contemporary mural paintings. E-Preserv Sci. 2013;10:10-8.

38. Wang SF, et al. Synthesis of cross-shaped PbS nanostructures by a surfactant-assisted reflux process. Mater Lett. 2006;60(21):2759-63.

39. Pimpinelli A, Villain J. Physics of crystal growth. Cambridge: Cambridge University Press; 1998.

40. de la Rie ER, Michelin A, Ngako M, Del Federico E, Del Grosso C. Photocatalytic degradation of binding media of ultramarine blue containing paint layers: a new perspective on the phenomenon of 'ultramarine disease' in paintings. Polym Degrad Stab. 2017;144:43-52.

41. Modugno F, Di Gianvincenzo F, Degano I, van der Werf I, Bonaduce I, van den Berg KJ. On the influence of relative humidity on the oxidation and hydrolysis of fresh and aged oil paints. Nature. 2019;9(55333):1-16.

42. Grech C, Tse N, Doronila A, Duan X, Ahmad A, Isa MM. Chapter 33: a preliminary investigation into the behavior of modern artists' oil paints in a hot and humid climate. In: van den Berg KJ, Bonaduce I, Burnstock A, Ormsby B, Scharff M, Carlyle L, Heydenreich G, Keune K, editors. Conservation of modern oil paintings. Switzerland: Springer; 2019. https://doi. org/10.1007/978-3-030-19254-9.

43. Ormsby B, Lee J, Bonaduce I, Lluveras-Tenorio A. Evaluating cleaning systems for use on water sensitive modern oil paints: a comparative study. In: van den Berg KJ, Bonaduce I, Burnstock A, Ormsby B, Scharff M, Carlyle L, Heydenreich G, Keune K, editors. Conservation of modern oil paintings. Berlin: Springer; 2019. p. 11-38.

\section{Publisher's Note}

Springer Nature remains neutral with regard to jurisdictional claims in published maps and institutional affiliations.

\section{Submit your manuscript to a SpringerOpen ${ }^{\circ}$ journal and benefit from:}

- Convenient online submission

- Rigorous peer review

- Open access: articles freely available online

- High visibility within the field

- Retaining the copyright to your article

Submit your next manuscript at $\boldsymbol{\nabla}$ springeropen.com 